\title{
Satellite observations of phytoplankton enrichments around seamounts in the South West Indian Ocean with a special focus on the Walters Shoal
}

\author{
Demarcq Hervé ${ }^{1,2,{ }^{*}}$, Noyon Margaux ${ }^{3}$, Roberts Michael J. ${ }^{3,4}$
}

\author{
${ }^{1}$ MARBEC, Univ Montpellier, CNRS, Ifremer, IRD, Sète, France \\ 2 Institut de Recherche pour le Développement (IRD), Marseille, France \\ ${ }^{3}$ Ocean Science \& Marine Food Security, Nelson Mandela University (NMU), Port Elizabeth, South \\ Africa \\ ${ }^{4}$ National Oceanography Centre (NOC), Southampton, United Kingdom \\ * Corresponding author : Hervé Demarcq, email address : herve.demarca@ird.fr
}

\begin{abstract}
:
Spatial anomalies associated with seamounts and islands have been detected in the South West Indian Ocean using a new surface chlorophyll-a based enrichment index (EI). Calculated from daily L3 4-km MODIS chl-a data from 2003 to 2018, the El was used to quantify recurrent (seasonal) surface enrichment associated with these features. Most notable were the shallow Walters Shoal $(18 \mathrm{~m})$ and nearby deeper WS-2 seamount $(480 \mathrm{~m})$, both located on the southern Madagascar Ridge, which showed high El values of $40 \%$ and $15 \%$ local enhancement. Tromelin Island, east of Madagascar, exhibited more moderate values of $15 \%$ local increase. Other shallower seamounts including La Pérouse $(60 \mathrm{~m})$ and MAD-Ridge $(240 \mathrm{~m})$ exhibited sporadic or no measurable surface maxima. Regions of strong mesoscale activity such as south of Madagascar where the South East Madagascar Current detaches from the continent also revealed high El values. A marked seasonality of the El was observed over the Walters Shoal, with higher values during the oligotrophic season than in the austral winter. The seasonal variability of the MLD in combination with the seamount bathymetry appears to induce the thermal and biological anomalies observed there, possibly favoured by the presence of a Taylor cap at the summit. Ship-collected in situ measurements showed the satellite observed enrichment to be associated with shallowing of the deep chlorophyll maximum, as well as a shift of phytoplankton groups towards diatoms and small flagellates. No net increase of integrated chl-a was measured but a potential doubling in primary productivity is expected. The El developed in this study, designed to reveal sporadic, small localised chl-a maxima, is likely applicable to other areas in the ocean where there is local enrichments.
\end{abstract}

Keywords: SWIO, Chlorophyll-a, Remote sensing, MODIS-Aqua, Geostrophic currents, Deep chlorophyll maximum 


\section{Introduction}

45 Increasing threats such as fishing and mining, as well as the need for ecological understanding and conservation, have led to significant research efforts into seamount ecosystems in recent decades (e.g. Keating et al., 1987; Rogers, 1994, 2018; Yesson et al., 2011; Fock, 2012). In particular, Clark 
et al. (2008) and Rogers (2018) demonstrated the ecological function of oceanic seamounts and their specificity in terms of pelagic and benthic components, and their connectivity with other seamounts or coastal systems (Shank, 2010; Miller and Gunasekera, 2017). Moreover, it is commonly assumed that seamounts favour local increases in biological diversity and productivity at the base of the food chain (Genin, 2004; Samadi et al., 2006; Genin and Dower, 2007; Rowden et al., 2010), although the latter has been challenged by the lack of evidence (Clark et al., 2010).

55 A wide variety of underlying mechanisms are potentially responsible for favouring biological enrichment over seamounts. The most common is isopycnal doming associated with a homogeneous amplified flow over a seamount (Odate and Furuya, 1998), sometimes reinforced by the presence of a Taylor cap (Chapman and Haidvogel, 1992; Mohn and Beckmann, 2002). This moves cooler, deeper water rich in nutrients into the photic zone. Tidal amplification or rectification inducing internal wave generation (Hunkins, 1986; Beckmann and Mohn, 2002) or bottom-trapped waves (Brink, 1989) are also responsible for local effects on movement and retention of water and particles respectively. More often, a combination of different processes occur simultaneously, with each seamount being unique as a result of its morphology, depth, latitude and environment.

65 Few studies however, have been able to clearly demonstrate a significant local increase in phytoplankton biomass or productivity induced by seamounts. One of the first based on field sampling at the Minami-kasuka seamount in the northwestern Pacific (Genin and Boehlert, 1985) observed modifications in the vertical structure of chlorophyll-a (hereafter chl-a) associated with the seamount. Other in situ measurements detected a significant increase in local chl-a concentration,

70 coupled with changes in the vertical distribution, mostly for seamounts interacting with the euphotic layer, such as the Cobb seamount (Dower et al., 1992; Comeau et al., 1995) and the Komahashi No. 2 seamount in the Pacific (Odate and Furuya, 1998) as summarized in Genin and Dower (2007). More recently in the South West Indian Ocean (SWIO), Sonnekus et al. (2017) found a positive response of phytoplankton on several shallow (<200 m) seamounts mostly along the Southwest

75 Indian Ridge. Yet, as stated by Rogers (2012), few studies have shown the persistence of phytoplankton enrichment and its effect on primary productivity, leaving the issue largely open to question (Genin and Dower, 2007; Clark et al., 2010). Several studies have shown well-defined intermittent enrichment around seamounts (e.g. Genin and Boehlert, 1985; Boehlert and Genin, 1987; Mouriño et al., 2001; Genin and Dower, 2007), but the spatio-temporal variability of the

80 enrichment is difficult to assess because of a lack of concurrent measures away from the seamounts. For instance, at two North Atlantic seamounts, Arístegui et al. (2009) showed that the average plankton living biomass including metabolic rates were not significantly different on and away from the seamounts, likely because of the large spatio-temporal variability observed around them. More recently, trophic interactions within the pelagic community analysed from stable isotope ratios $\left(\delta^{13} \mathrm{C}\right.$ 85 and $\delta^{15} \mathrm{~N}$; Denda et al., 2017) have failed to reveal significant autochthonous seamount production relative to the open ocean.

The lack of a clear seamount effect is often attributed to the strong influence of mesoscale circulation around seamounts. This typically has variance at shorter time-scales than the duration of 90 the ship surveys, making it difficult to detect and assess seamount effects (Dower et al., 1992; Comeau et al., 1995; Odate and Furuya, 1998). This emphasizes the importance of choosing 
adequate time-scales when sampling seamounts during oceanographic surveys (Mouriño et al., 2001). Remote sensing ocean colour measurements, although integrated in the upper part of the euphotic layer, however overcome this problem and are able to measure changes in chl-a concentration with wide and synoptic coverage (Gordon and Morel, 1983). In this context, Oliveira et al. (2016) used satellite-derived chl-a data to detected positive influences on primary production at two shallow seamounts off Portugal, supported by a large collection of in situ measurements. Moreover, using only MODIS chl-a data, Lemos et al. (2018) successfully showed a doubling of the chl-a concentration during spring blooms over a group of coastal shallow seamounts in the tropical Atlantic.

In the SWIO, seamounts are spread across a large range of latitudes and oceanographic systems, resulting in contrasting environments (Fig. 1). Many are situated in areas beyond national jurisdiction (ABNJs; Kitchingman et al., 2007) and hence very remote, explaining why they are poorly explored (Rogers, 2012). Attempting to rectify this situation, Rogers et al., (2017) launched one of the largest modern field campaigns in the SWIO using the RV Dr Fridtjof Nansen (Expedition 410) in 2009. This surveyed the benthos and pelagic environments of six deep seamounts on the Southwest Indian Ridge (Rogers et al., 2017). This expedition was followed by the MADRidge project in 2016 (Roberts et al., this issue) which focused attention mostly on the

110 little known Madagascar Ridge north of the SW Indian Ridge. The Ridge is a submerged extension of the Madagascar landmass. Two clusters of mostly deep seamounts are found at either end of this ridge, with each having a seamount that reaches into the upper euphotic layer of the ocean. Also of interest is a shallow seamount called La Pérouse to the east of Madagascar (northwest of Réunion Island) on the Madagascan Plain.

115

A series of ship surveys were carried out on the three shallowest seamounts in 2016 and 2017, namely La Pérouse (60 m) in September 2016 (https://doi.org/10.17600/16004500), an unnamed pinnacle on the northern Madagascar Ridge in November/December 2006, thereafter named "MAD-Ridge" (240 m) (https://doi.org/10.17600/16004800 and https://doi.org/10.17600/16004900)

120 and the Walters Shoal seamount $(18 \mathrm{~m})$ on the southern part of the Ridge from 30 April to 13 May 2017 (https://doi.org/10.17600/17002700).

This paper is a contribution to the MADRidge project complementing the ship surveys with satellite observations. It focuses mainly on the cruise targeted seamounts. The rationale was to explore the

125 hypothesis articulated by several authors in the past - Genin and Boehlert (1985), Dower et al., (1992), Rogers (1994) and Genin and Dower (2007) - that seamounts can significantly contribute to local enhancement in phytoplankton biomass and potentially increase primary production. An important part of this exploration was to see if satellite observations can be used to identify the local enrichment of chl-a, transient in nature, at the small spatial scales associated with seamounts

130 dynamics. We do this using a newly created 'enrichment' index (based on L3 4-km MODIS data) generated for the entire SWIO area. This enhances signals that otherwise become poorly detectable using common technique like averaging. We are then able to zoom into small areas around seamounts and detail chl-a and SST patterns with their seasonal dynamics. But the analysis also draws attention to the small Tromelin Island east of Madagascar and a deeper (480 m) side 
135 seamount situated $100 \mathrm{~km}$ south-east of the Walters Shoal at $34^{\circ} 00^{\prime} \mathrm{S}-44^{\circ} 35^{\prime} \mathrm{E}$, where we surprisingly detected seasonal chl-a enhancement. We reference this as WS-2.

\section{Data and methods}

\section{$140 \quad 2.1$ Theoretical probability of a Taylor cap}

To test in theory whether a 'Taylor cap' could form at the four seamounts and contribute to local enrichment, we used criteria computed by Chapman and Haidvogel (1992) and summarized in White et al. (2007). Two criteria were calculated for the Walters Shoal, WS-2, MAD-Ridge and La

145 Pérouse seamounts, namely (1) the Rossby number, $R o\left(=U /\left(f^{*} L\right)\right.$, where $U$ is the average current speed, $f$ the Coriolis parameter and $L$ the width of the seamount) and (2) the Blocking parameter $(B l)$, which is the ratio of the relative seamount elevation above the sea floor $(h 0 / H$, where $h 0$ is the seamount elevation above the seafloor at depth $H$ ) relative to Ro (Huppert, 1975; Chapman and Haidvogel, 1992; Roden, 2013). The range of current speed (U) at each seamount has been

150 estimated from in situ ADCP measurements at each seamount. Uncertainties on seamount actual topography (depth of the bases $(\mathrm{H})$ and summit $(\mathrm{h})$ ) have also been considered for the Taylor cap assessment.

\subsection{Remote sensing data}

In this study eight remote sensing datasets were used. For the large-scale SWIO analyses we used daily L3 data of chl-a and sea surface temperature (SST) collected by the MODIS (Moderateresolution Imaging Spectroradiometer) sensor on board the Aqua platform (downloaded from https://oceancolor.gsfc.nasa.gov/, last accessed 27/02/2019). This has a spatial resolution of $1 / 24^{\circ}$

160 (ca. 4.5-5 km). The full MODIS-Aqua mission period from July 2002 to December 2018 was downloaded. For the periods covered by the three cruises in 2016 and 2017 we used daily L2 orbit data of chl-a and Remote Sensing Reflectance with a resolution of $1.1 \mathrm{~km}$ resolution $\left(1 / 96^{\circ}\right)$. Data on Photosynthetic Available Radiation (PAR) were extracted from the model of Frouin et al. (2012) accessed at https://oceandata.sci.gsfc.nasa.gov/MODIS-Aqua/Mapped/Daily/4km/par/. We further

165 use the penetration depth of the sensor signal (the inverse of the Diffuse attenuation coefficient for downwelling irradiance), measured at $490 \mathrm{~nm}$ and computed from the empirical formulation of Werdell and Bailey (2005).

For circulation we use reprocessed daily L4 geostrophic currents extracted from the CMEMS

170 (Copernicus Marine Environmental Service) database of altimetry data product “SEALEVEL_GLO_PHY_L4_REP_OBSERVATIONS_008_047” (http://marine.copernicus.eu, last accessed 27/02/2019). These data span from 1993 to 2018 and have a spatial resolution of $0.25^{\circ}$. A monthly climatology of the geostrophic Kinetic Energy (KE) was computed from daily-interpolated geostrophic current data between 1993 and 2018. This eliminates the mesoscale energy component 175 that otherwise dominates some of the studied regions.

Daily surface wind vector (gridded) data were taken from the CCMP (Cross-Calibrated MultiPlatform) V2.0 made available by the Remote Sensing Systems (RSS). This product combines 
radiometer and scatterometer wind speed with moored buoy wind data and ERA-Interim model wind fields using a Variational Analysis Method (VAM). It has a spatial resolution of $0.25^{\circ}$. The data were downloaded from http://www.remss.com/measurements/ccmp/ (last accessed 27/02/2019). Monthly arithmetic averages were calculated from daily fields to describe the seasonal wind dynamics over the study region.

\subsection{In situ data}

In order to describe the climatological seasonal cycle of the Mixed Layer Depth (MLD), we used the DT02 climatological version from the de Boyer Montégut atlas (de Boyer Montégut et al., 2004) (http://www.ifremer.fr/cerweb/deboyer/mld/Surface_Mixed_Layer_Depth, last accessed

190 27/02/2018), based on historical observations. This climatology is defined by a $1^{\circ}$ grid with a fixed threshold temperature criterion of $0.2^{\circ} \mathrm{C}$ absolute difference from surface (DT).

Other than the above, only in situ data collected by the Walters Shoal cruise were used in our study. Salinity, temperature and depth data were collected using a SeaBird Electronics SBE911+ CTD completed with two SBE43 dissolved oxygen sensors and a WET Labs ECO-FL-NTU fluorimeter. Vertical profiles of chl-a were calculated from the CTD fluorescence data calibrated with HPLC phytoplankton pigment measurements from samples taken at different depths at each CTD station. The determination of four major phytoplankton groups (diatoms, peridinin-containing dinoflagellates, small flagellates and prokaryotes) was made from their characteristic diagnostic

200 pigments (either photosynthetic or photoprotective) taken from the HPLC measurements defined in Barlow et al. (2010) for the Agulhas ecosystem. The deep chlorophyll maximum (DCM) was defined as the depth of the chlorophyll maximum value using a $5 \mathrm{~m}$ moving average to smooth the high frequency vertical variability. Nitrate, silicate and phosphate concentrations were determined from samples collected between the surface and $200 \mathrm{~m}$ using standard Niskin bottles.

To distinguish the seamount effect from the background environment, all physical and biological variables were averaged in two areas around each seamount: (1) within a radius of $30 \mathrm{~km}$ from the seamount centre, and (2) between the radii of 30 and $90 \mathrm{~km}$. The exceptions were wind speed and MLD which had a low resolution $1 / 4^{\circ}$ and $1^{\circ}$ respectively.

\subsection{Preliminary checking MODIS reflectance}

Previous bathymetric surveys (e.g. Cruise MD208, https://doi.org/10.17600/17002700) showed the summit of the Walters Shoal to be relatively flat with a highpoint reaching $18 \mathrm{~m}$ below the sea

215 surface. The central part comprises a caldera with an average depth of $50 \mathrm{~m}$. The oligotrophic nature of this region means the water is exceptionally clear, characterized by an optical depth up to $50 \mathrm{~m}$. This influences the water colour signal observed by the MODIS sensor which potentially can be altered by the seabed albedo through the water column.

220 In this study, we commonly observed an overlap between the high surface chl-a signature and the shallow bathymetry of the Walters Shoal, as shown in Fig. 2 for 5 January 2016. The shape of the reflectance spectra associated with this high chl-a at the seamount summit is used to test a potential 
biais in the remote sensing response due to the shallow bathymetry (bottom detection effect). Three locations up to depths of $\sim 500 \mathrm{~m}$ were selected (Fig. 2A) to cover the range of surface chl-a levels observed near the seamount, i.e. from the local maximum observed at the border of the seamount plateau $\left(0.35 \mathrm{mg} \mathrm{m}^{-3}\right.$, location 1$)$ to a typical oligotrophic value $\left(0.07 \mathrm{mg} \mathrm{m}^{-3}\right.$, location 3$)$ with an intermediate value $\left(0.15 \mathrm{mg} \mathrm{m}^{-3}\right.$, location 2$)$.

The three corresponding spectra of MODIS reflectance (plain green lines in Fig. 2B) show typical spectral profiles of 'Case 1' water, i.e. whose optical properties are only influenced by phytoplankton pigment assemblages dominated by chl-a, as shown by the reference model of Morel and Maritorena (2001). This is illustrated by the shape of the dotted line for value $0.1 \mathrm{mg} \mathrm{m}^{-3}$ in Fig. 2B. The extracted spectra are in the range of variability of this reference spectra, especially for bands 443, 488 and $548 \mathrm{~nm}$ (black bars in Fig. 2B) used by the MODIS OC3M chl-a algorithm.

235 They all vary in a manner similar to the modelled chl-a reference spectra, with a typical minimum of variability at $530 \mathrm{~nm}$. In particular, the spectral profile selected over the seamount (dark green plain line in Fig. 2B) varies in the same way as the other two, denoting an absence of influence by the seamount which, otherwise, can alter the validity of the chl-a MODIS values.

240 Secondary differences also occur between the MODIS reflectance and the reference spectra at wavelengths $>548 \mathrm{~nm}$, either due to the absorption by pigments other than chl-a and/or to partially uncorrected atmospheric effects in the MODIS reflectance. We can therefore conclude that there is no influence of the shallow seamount bathymetry on the quality of the remote sensing reflectance and specially on the derived chl-a.

\subsection{Computation of a spatial enrichment index (EI)}

As the best case for seamounts in the SWIO, we observed locally elevated and contrasting patterns of chl-a (values $>0.2 \mathrm{mg} \mathrm{m}^{-3}$ ) in the MODIS ocean colour data over the Walters Shoal (Fig. 3),

250 especially in summer when the average surface chl-a in the region is $<0.15 \mathrm{mg} \mathrm{m}^{-3}$. Chl-a signals at other sites were not as strong, and therefore difficult to recognise or distinguish. To properly assess whether the SWIO seamounts actual generate local primary production, we therefore needed to find a way of enhancing these weak signals. We started with the stronger Walters Shoal signals using a set of cloud-free, 1-km resolution, MODIS L2-data scenes in 2016 (Fig. 3). From these we aimed to

255 develop a generic index to represent local enhancement (enrichment).

We first defined, at the pixel level, a circular region well away from each candidate data pixel (white shaded disc in Fig. 3 and hatched area in Fig. 7B) to serve as an external reference. This 'External' reference region however, had to be close enough to the candidate pixel to represent its

260 oceanic surrounding, but far enough away to minimize the influence of the local enrichment pattern (potentially induced by the seamounts as shown in Fig. 3). All pixel values (chl-a) in the External reference area are averaged to one value. An 'enrichment index', or EI used henceforth, is then computed as the difference between the candidate pixel value and its 'External' average value. This amplifies any signature of local enhancement (enrichment). It is important to note that the candidate 265 pixel remains at the centre and therefore the white shaded disc (average area) moves accordingly for every new candidate pixel calculation. 
The Enrichment Index (EI) is therefore calculated as:

$$
E I_{(\text {lat, Ion) }}=c h l a_{(\text {lat, Ion) }}-\sum_{i=R 1}^{R 2} \frac{c h l a_{i}}{n}
$$

270 where R1 and R2 are the two distances from the candidate pixel, and $\mathrm{n}$ is the number of pixels in the External reference area.

A wide combination of distances for R1 (from 10 to $50 \mathrm{~km}$ ) and R2 (from 50 to $120 \mathrm{~km}$ ) were tested for the whole study area in Fig. 1, using the entire 4-km resolution data set comprising 5844

275 daily situations between 2003 and 2018. It appears that an interval distance of $30( \pm 10) \mathrm{km}$ to 90 $( \pm 20) \mathrm{km}$ is adequate to discriminate all the patterns observed, with a similar contrast (signal/noise ratio). The large size of the reference area $(n=1144$ pixels in our case) strongly minimizes the influence of extended patterns of elevated chl-a within this reference area. Nevertheless, because large signatures extending up to $100 \mathrm{~km}$ from the seamount are commonly observed (Fig. 3), the 280 resulting index must be considered as a minimum value of the local increase. Because they are not supposed to be related to the signature of local enrichment, negative values of the index (i.e. attributable to local minima of chl-a or to any higher value within the surrounding area) were not considered. For this reason, the minimum value of the enrichment index (EI) is on average between 5 and $6 \%$, a value that corresponds in our computation to an absence of detectable enrichment.

Surface cooling effects are also known to be associated with seamounts when a change in biomass or productivity is observed, specially over shallow seamounts (Mouriño et al., 2001; Oliveira et al., 2016). We therefore computed an equivalent "cooling index" from MODIS SST, based on the same spatial criteria above. We do not use an abbreviation acronym in this paper for this.

\subsection{Computation of Primary production}

We used the bio-optical model described in Demarcq et al. (2009) to estimate the primary production (PP) in situ vertical profiles of chl-a, later discussed in section 4.5. This model uses the calibrated chl-a for the 22 fluorescence profiles of the Walters Shoal cruise (summarized in Table 1) along with the satellite-estimated PAR for the light at the sea surface (see section 2.2) and an exponential light attenuation computed every meter down to $200 \mathrm{~m}$. The accuracy of such model, mostly used in coastal areas, was not proven in oligotrophic waters but we only use it here to estimate relative increases in PP in response to changes in light conditions related to the Walters Shoal seamount.

\section{Results}

\subsection{Surface Chlorophyll-a and enrichment index patterns in the SWIO}

\subsubsection{Average and variability of the surface chlorophyll-a}


The annual average chl-a concentration in the SWIO is shown in Fig. 4. Well-known oligotrophic characteristics are clearly seen north of $30^{\circ} \mathrm{S}$ with average surface chl-a concentrations ranging

310 between 0.05 and $0.2 \mathrm{mg} \mathrm{m}^{-3}$. The coastal margins are mostly dominated by local enrichment (i.e., chl-a $>0.3 \mathrm{mg} \mathrm{m}^{-3}$ ). The La Pérouse seamount and Tromelin Island lie in one of the most oligotrophic regions of the Indian Ocean subtropical gyre. The MAD-Ridge seamount, immediately south of the Madagascar shelf, is situated in an intermediate region under the direct influence of the South East Madagascar Current (Nauw et al., 2008). The Walters Shoal, situated on the boundary of

315 the subtropical gyre, experiences a subtropical climate and has a more marked seasonality than farther north, with chl-a varying from 0.10 to $0.25 \mathrm{mg} \mathrm{m}^{-3}$. Fig. 4 also shows some shallower seamounts and shoals in the region (yellow frames) with the highest chl-a values in the vicinity of the shallow Central Mascarene Ridge. In the Mozambique channel, the Bassas da India atoll, Lazarus Bank, Banc du Geyser-Zélée and the Castor Bank also show discernible local enrichment.

320 Similarly, several islands in the region (orange frames) display a visible chl-a signal mostly notably Juan de Nova, Comores and the Glorieuses islands. Interestingly, the small island of Europa (8 km wide) does not show any signature, at least on the yearly average climatology.

A more detailed examination of the annual chl-a average in the Walters Shoal region (Fig. 4B) has

325 shown that the tiny local but discernible increase in chl-a observed was well aligned with the bathymetry of the shoal. Here chl-a values slightly more than $0.18 \mathrm{mg} \mathrm{m}^{-3}$ were associated with depths $<200 \mathrm{~m}$, while chl-a values of $0.17 \mathrm{mg} \mathrm{m}^{-3}$ were found to depths of $\sim 1000 \mathrm{~m}$. These values are similar to those found some $200 \mathrm{~km}$ farther south. This is also supported by the high frequency CV (computed from daily data) of the chl-a (Fig. 4C) which shows a well-defined local minimum

$330<0.3 \mathrm{mg} \mathrm{m}^{-3}$ clearly centred on the Walters Shoal, within the $500 \mathrm{~m}$ isobath, compared with $0.5 \mathrm{mg}$ $\mathrm{m}^{-3}$ farther offshore. None of the other seamounts or shoals in this study show similar increased chla or a local minimum of variability.

\subsubsection{Specific chlorophyll-a patterns and vertical structure at the Walters Shoal}

335 Systematic examination of high resolution 1-km daily MODIS chl-a data (Fig. 3, Fig. 5) shows typical events of local enrichment during the austral summer with chl-a plume concentrations between 0.2 to $0.5 \mathrm{mg} \mathrm{m}^{-3}$ relative to background values of $\sim 0.07 \mathrm{mg} \mathrm{m}^{-3}$. For all situations explored, the chlorophyll plumes originated from the summit or flanks of the seamount, and were dispersed by the local geostrophic current field (white arrows in Fig. 3). The average current speed

340 was typically $\sim 0.1 \mathrm{~m} \mathrm{~s}^{-1}$ with plume lengths extending between 40 and $150 \mathrm{~km}$, suggesting these structures could last between 5 and 14 days.

The Walters Shoal cruise took place during the decreasing phase of the enrichment period at the seamount, when the climatological value of the MLD was about $60 \mathrm{~m}$, in its seasonal growing phase (the latter is discussed from Fig. 9 later). Seven calibrated vertical chl-a profiles measured during

345 the cruise were directly compared with "surface" values in the MODIS chl-a data for four cloudfree days (Fig. 5). Corresponding vertical profiles of temperature and nitrate concentration are reported in Fig. S1, in the Supplementary material. Three different situations are noted. First, a possible seamount-induced enrichment at station 2 (Fig. 5A insert) near the $200 \mathrm{~m}$ isobath which has a chl-a maxima between the depths of $20 \mathrm{~m}$ and $50 \mathrm{~m}$. The water mass was very homogeneous 350 with a temperature of $20.3^{\circ} \mathrm{C}$ at the surface and $19.5^{\circ} \mathrm{C}$ at $80 \mathrm{~m}$, suggesting intense vertical mixing. The surface nitrate concentrations measured at $8-10$ different depths between the surface and $200 \mathrm{~m}$ 
(see Fig. S1, station 2) increased from 0.5-1.0 $\mu \mathrm{mol} \mathrm{kg} \mathrm{kg}^{-1}$ at 5-20 $\mathrm{m}$ (DCM depth) to reach $2 \mu \mathrm{mol}$ $\mathrm{kg}^{-1}$ at $50 \mathrm{~m}$ at the bottom of the DCM), i.e. far from a depleted state, even near the surface. There is good agreement between the surface chl-a value of $0.13 \mathrm{mg} \mathrm{m}^{-3}$ and the satellite-measured chl-a (exponentially depth-integrated up to approximately $30 \mathrm{~m}$ ) of $0.15 \mathrm{mg} \mathrm{m}^{-3}$.

The second type of profile is seen at stations 18, 19, 21 and 22 (Fig. 5B to 5D), away from the seamount summit over depths from 800 to $1000 \mathrm{~m}$. The thermal profile (see Fig. S1) is quite different to the near-summit stations with warmer values close to $21.0^{\circ} \mathrm{C}$ in the surface layer. The thermocline occurs between $30 \mathrm{~m}$ to $60 \mathrm{~m}$ with a DCM depth between 40 and $75 \mathrm{~m}$ among the four stations. Nitrate is fully depleted at depths between 20 and $50 \mathrm{~m}$.

The third type of profile represented by stations 20 and 23 is similar to the offshore conditions and found in the depth range1000-1200 m. Surface chl-a ranges between 0.04 and $0.07 \mathrm{mg} \mathrm{m}^{-3}$ at the

365 surface with the DCM between $80 \mathrm{~m}$ and $85 \mathrm{~m}$. MODIS data indicate an optical depth-integration of approximately 40 and $50 \mathrm{~m}$ for yields of 0.07 and $0.10 \mathrm{mg} \mathrm{m}^{-3}$ respectively. The surface temperature (see Fig. S1) at station 23 is $>21^{\circ} \mathrm{C}$ with a DCM around $85 \mathrm{~m}$ and full nitrate depletion at $80 \mathrm{~m}$ and above. Station 20 (Fig. 5C) shows a slightly sharper DCM at $80 \mathrm{~m}$ and a similar surface temperature $\left(<21^{\circ} \mathrm{C}\right)$, with a more homogeneous surface layer and a less prominent thermocline.

370 Nitrate in the upper part of the DCM is not fully depleted at $70 \mathrm{~m}$.

To test the robustness of this observed spatio-temporal variability, we also considered all 22 stations where CTD and chl-a profiles were measured during the 13-day long Walters Shoal cruise (Fig. 6A). We computed the average EI for the duration of the cruise as well as the average geostrophic current (background image and white arrows in Fig. 6A). Despite the modest number of stations, spatial sampling allowed a precise description of the main enrichment gradient.

We partitioned the vertical profiles according to their distance from the seamount: i) those considered with minimal (or no) influence by the seamount, with depths $>800 \mathrm{~m}$ (Figs. 6A blue crosses, blue curve, $n=4$ ), ii) those close to the seamount with depths $<600 \mathrm{~m}$ (green crosses, green curve, $n=11$ ) and iii) an intermediate set of profiles situated between depths from 600 to 800 $\mathrm{m}$ (red crosses, red curve, $\mathrm{n}=7$ ). Each type of profile can be summarized by its average (Fig. 6C, solid lines) and standard deviation (Fig. 6C, coloured shading). The DCM, the integrated chl-a content and the primary production estimated from the bio-optical model are summarized in Table 385 1. The integrated chl-a was found between 20 and $40 \mathrm{~g} \mathrm{~m}^{-2}\left(24.6 \pm 5.9 \mathrm{mg} \mathrm{m}^{-2}\right)$ with no noticeable differences found between the three categories (Table 1).

The in situ pigment analysis from the HPLC measurements (see data summary in Table 2) shows small flagellates to clearly dominate $(61 \%)$ at all stations, followed by prokaryotes $(31 \%)$, diatoms $390(5 \%)$ and dinoflagellates (3\%). Diatoms and small flagellates increased towards the seamount (horizontal arrows) while dinoflagellates and prokaryotes were more abundant at stations farthest from the seamount. We also found important differences between the surface layer and the DCM (vertical arrows), with greater abundance of dinoflagellates and prokaryotes at the surface (the inverse for small flagellates) and diatoms almost evenly distributed between both layers. 


\subsubsection{Spatial variability of the enrichment index (EI)}

The annual average of all daily EIs computed for the whole SWIO region (Fig. 7), shows most major seamounts or shoals to have maxima well above the background value of 5-6\% (see methods). The method suitably enhances local contrast compared with simple chl-a averages (Fig.

400 4). Certainly, large plateaus such as the central Mascarene Ridge standout more starkly. Walters Shoal shows a well-defined EI maximum $>30 \%$ precisely over the summit (Fig. 7C). Local enrichment at other seamounts such as the Rodrigues Ridge (a westward extension of the Rodrigues bathymetric structure) and the Soudan Bank are also clear and comparable in intensity to the Walters Shoal signature. These were surprisingly not visible in the chl-a averages (Fig. 4). Other seamounts in the Mozambique Channel are similarly emphasised. Here we refer to the Bassas de India atoll, Lazarus Bank, Geyser Bank and Castor Bank which all have maximum EI values $>40 \%$. Noticeable exceptions in Fig. 7 are the MAD-Ridge and La Pérouse seamounts where no signal was found.

410 Small flat islands of similar size such as the semi-submerged Bassas da India atoll (10-12 km wide) and Europa Island ( $8 \mathrm{~km}$ wide), show different effects, the former with a wide spatial signature (about $30 \mathrm{~km}$ ) and the latter a lesser intense signal (Fig. 7). Tromelin Island which is $1 \mathrm{~km}$ in its longest dimension, shows a tiny but well-defined signature.

415 Many other features not related to islands or seamounts are also highlighted by the EI defined here. These include the signature of the South East Madagascar Current which flows (on average) close to the continental shelf and seen to be well separated from the wind-driven coastal chlorophyll enrichment on the Madagascar shelf.

\section{3.1.4 Seasonal variability of the enrichment index (EI)}

The spatio-temporal seasonality of the EI for the Walters Shoal seamount was described through a monthly climatology (arithmetic mean), computed from all daily situations between 2003 and 2018 (Fig. 8). The EI appears to be highly seasonal with high values from November to April, and the same spatial characteristics as those described from the annual average, i.e. with a clear maximum

425 associated with the 200-500 m isobath area. In contrast, from late June to August, a local minimum over the seamount is visible with little enrichment observed elsewhere in the region (Fig. 8).

September intriguingly corresponds to a transitional period with widespread enrichment marked with a local EI minimum over the seamount.

430 Of great interest, WS-2 situated $140 \mathrm{~km}$ south-east of the Walters Shoal with a summit $480 \mathrm{~m}$ below the surface (see frame in Fig. 1), does display a discernible signature. This signature is also present on the annual average (inserted frame in Fig. 7C), despite a clear seasonal maximum only visible from November to April (Fig. 8 and Fig. S2).

435 The data set of the monthly climatology (2003-2018) of this enrichment index as well as its annual average can be found online at https://doi.org/10.5281/zenodo.3776377.

\subsection{Other environmental parameters}


The cooling index averages (Fig. S3) indicate an annual average cooling of $0.4^{\circ} \mathrm{C}$ over the Walters Shoal. Surface cooling is not observed at the other seamounts notably at MAD-Ridge (see insert) and La Pérouse. Thermal anomalies of most islands are moderate on average (La Réunion, Bassas da India atoll, Cargados Carajos Shoal, Soudan Bank), but sometimes acute such as at the Comores islands. Numerous cooling areas are visible around Madagascar (note the southeast upwelling near Fort Dauphin) as well as associated with several regions along the African shelf break.

\subsubsection{Taylor Cap existence and average kinetic energy (KE)}

The results pertaining to the possible existence of a Taylor cap (see Methods) at the four seamounts 450 are summarized in Table $\mathrm{S} 1$. The bold values indicate the potential existence of this feature for varying current speeds as recommended by White et al. (2007), i.e. Ro $<0.15-0.2$ and Bl $>2$. Accordingly, only the Walters Shoal and WS-2 are likely to have a (semi) permanent Taylor cap.

The annual average of the Kinetic Energy (KE) (Fig. S4) highlights the existence of wide zonal minima, and hence low-speed currents, in the southern part of the SWIO, encompassing the Walters Shoal where $\mathrm{KE}<0.01 \mathrm{~m}^{2} \mathrm{~s}^{-2}$. As shown by the white dotted transect between 40 and $60^{\circ} \mathrm{E}$ in Fig. $\mathrm{S} 4 \mathrm{~B}$, a longitudinal current speed minimum is observed at the exact position of the Walters Shoal seamount where currents are $<0.1 \mathrm{~m} \mathrm{~s}^{-1}$. Other KE minima are associated with the Mascarene Plateau and the Mascarene islands, with the noticeable exception of the topographical "strait" at the centre of the Mascarene Plateau where currents are accelerated.

\subsubsection{Seasonal variability at Walters Shoal}

In Fig. 9, we bring all the dynamics at the Walters Shoal together. The seasonal variability of seven oceanic variables is described for both the inner part (30 km from the seamount centre, solid lines) and the outer part (from $30 \mathrm{~km}$ to $90 \mathrm{~km}$ from the centre, dotted lines). Note that wind speed and the MLD are averaged for the total area $(0-90 \mathrm{~km})$. The period sampled by the cruise is represented by the vertical grey bar. Most variables show well-marked seasonal variability. For instance, the upper vertical structure of the ocean is characterised by the MLD (orange line) which is seen to vary between 20-35 m from November to March and then to $>50 \mathrm{~m}$ between April and October, peaking

470 at $100 \mathrm{~m}$ in July. This pattern corresponds with wind speed (black line) averages $>7.5 \mathrm{~m} \mathrm{~s}^{-1}$ from May to October, with a minimum of $6.5 \mathrm{~m} \mathrm{~s}^{-1}$ in December and a maximum of $8.5 \mathrm{~m} \mathrm{~s}^{-1}$ in July. Interestingly in these data, the average geostrophic current in the central part of the shoal (Fig. 9, solid brown line $)$ is very low $\left(0.08 \mathrm{~m} \mathrm{~s}^{-1}\right.$ on average, also see Fig. S4) with almost no seasonal variation. Away from the shoal the average velocity is not much different either with values between

4750.08 and $0.1 \mathrm{~m} \mathrm{~s}^{-1}$. However, the low resolution of the altimetry data maybe the cause of this. It is therefore likely that the real difference between these areas is much higher. The local decrease in current speed over the seamount summit (i.e., distance $<30 \mathrm{~km}$ ) relative to its immediate surroundings is on average $13 \% \pm 6 \%$ (Fig. 9 brown lines). This decrease represents only the central part of a much larger decrease of $43 \%$ which is observed along a full longitudinal transect at the latitude of the Walters Shoal (Fig. S4).

The SST cooling index associated with the seamount area (solid light blue line) also shows a strong seasonality with values $>0.2^{\circ} \mathrm{C}$ from October to March with a maximum $\sim 0.4^{\circ} \mathrm{C}$ in December and 
January. This same index was also computed for the outer part of the seamount (dashed light blue line) and did not show any seasonal pattern with a stable "background" value $\leq 0.2^{\circ} \mathrm{C}$.

The averaged chl-a over the seamount (solid green line) shows a classical summer minimum from December to May with average concentrations of $0.12 \mathrm{mg} \mathrm{m}^{-3}$ and a winter productive season from June to November with maximum average values of $0.26 \mathrm{mg} \mathrm{m}^{-3}$ in August and September. With 490 the exceptions of July and August, the values over the seamount are $15 \%$ higher than in the outer part (18\% from October to May), with a maximum increase of $26 \%$ in December.

Importantly, the variability of the enrichment index (EI) at Walters Shoal (Fig. 9, dark blue lines) shows a more contrasting seasonality (see also Fig. 8). The daily average EI varies mostly

495 oppositely to MLD and chl-a, with a minimum of a 5-8\% increase from June to August and relatively constant values of $19 \%$ from November to April. A maximum of $20 \%$ is observed in February. The relatively flat signal of the EI for the external part of the seamount (Fig. 9, dotted dark blue line), for which the minimum value of $5 \%$ is in July, can be ascribed to the baseline of the "environmental noise" of the index. This value differs from zero only because negative values of

500 the index are deliberately ignored (see Methods).

\section{Discussion}

\subsection{Geostrophic currents, Taylor caps and seamounts}

It is commonly accepted (Chapman and Haidvogel, 1992) that the formation of a Taylor cap can be a major source of biological enrichment at seamounts, (Dower et al., 1992), especially over midsize, isolated ones in steady stratified flow conditions. However, we must also recognize that turbulent mixing caused by seamount associated internal/baroclinic waves, and tidal mixing can be

510 equally important (Kunze and Sanford, 1996; Toole et al., 1997). In particular, (Koch-Larrouy et al., 2020, this issue) showed that the southern Madagascar Ridge is the site of strong vertical mixing attributable to internal tides and other non-linear processes. Unfortunately, no in situ mixing measurements were undertaken at the Walters Shoal during the cruise.

515 We have seen that the theoretical requirements for the existence of a Taylor cap (Table S1) are fully satisfied for the Walters Shoal and the WS-2 seamount. This is mostly due to their location in the Indian Ocean subtropical gyre where geostrophic currents are very low (Fig. S4). This was the case during the cruise where ADCP measurements indicated $<0.3 \mathrm{~m} \mathrm{~s}^{-1}$ (not shown). By contrast, the MAD-Ridge seamount mostly does not meet the Taylor cap criteria owing to persistent fast currents 520 and high mesoscale activity associated with the South East Madagascar Current (Lutjeharms et al., 1981) just north of the seamount (Fig. S4). We know from the study of six seamounts in the SWIO by Read and Pollard (2017), that the mean surface current in the region is dominated by mesoscale eddies with internal tides being the dominant topographic-driven processes at the seamount crests. In situ velocity measurements (Vianello et al., 2020, this issue) also indicate that the MAD-Ridge 525 seamount, at best, could experience a Taylor cap only $27 \%$ of the time. The La Pérouse seamount on the other hand, cannot maintain a Taylor cap owing to its small horizontal size. 
These results are consistent with the absence of surface chl-a increase at both the MAD-Ridge and La Pérouse seamounts (Fig. 7, Fig. S5, Fig. S6) despite numerous year-round remote sensing observations from 2003 to 2018. Similarly, no SST cooling was observed over these seamounts (Fig. S3), suggesting that very little cold water reaches the euphotic layer.

Because the Walters Shoal and WS-2 seamounts are situated in a relatively energetic region for baroclinic tides and internal waves (Simmons et al., 2004), it is highly likely that seamount-trapped waves, or rectified flow from tides as observed for many seamounts (Goldner and Chapman, 1997), could also coexist at these seamounts. At a larger scale, we found a $14 \%$ reduction in the geostrophic current close to the Walters Shoal relative to its immediate surroundings (Fig. 9, brown lines), probably because of barotropic currents in depths $<1000 \mathrm{~m}$ and to the frictional effects of the mesoscale eddies, whose trapped fluid is known to be effective up to depths of $240 \mathrm{~m}$ for cyclonic

540 eddies and $530 \mathrm{~m}$ for anticyclonic eddies (Chaigneau et al., 2011). The longitudinal current profile (Fig. S4B insert) showed a $43 \%$ decrease of the westward current speed from $0.14 \mathrm{~m} \mathrm{~s}^{-1}$ at $48^{\circ} \mathrm{W}$ to $0.08 \mathrm{~m} \mathrm{~s}^{-1}$ at the Walters Shoal $\left(44^{\circ} \mathrm{W}\right)$ with an increase thereafter. Significant topographic-induced current decreases were also observed at many other locations of the SWIO (Fig. S4), such as over the Mascarene Plateau. All these regions were similarly associated with high values of the

545 enrichment index (Fig. 7), highlighting that low geostrophic currents are a key factor supporting the biological responses to local enrichment.

Whatever the interplay between the different physical mechanisms involved at the Walters Shoal, geostrophic currents seem to dominate in the surface layer. In particular, enrichment observed from daily satellite observations (Fig. 3) show that the chl-a plumes over the seamount are always stretched in the direction of the geostrophic currents, sometimes in complex ways.

\subsection{Seasonal enrichments at the Walters Shoal}

555 The productive season at the Walters Shoal, well characterised by the surface chl-a concentration (Fig. 9, dotted green line), is in the austral winter from May to November. Values range with a maximum of $0.27 \mathrm{mg} \mathrm{m}^{-3}$ in August and a minimum of $0.08 \mathrm{mg} \mathrm{m}^{-3}$ in summer. These values are typical of boundaries of oligotrophic provinces and correspond to primary production values of $\sim 100 \mathrm{gC} \mathrm{m}^{-2}$ year $^{-1}$ (Behrenfeld and Falkowski, 1997). This winter maximum takes place one

560 month after the maximum of the MLD (in July), itself generated with another one-month lag by the intense mixing resulting from southwesterly winds (Fig. 9, black line). The bloom initiation is a response to the progressive deepening of the mixed layer at the onset of winter (March-June), and in accordance with the "Dilution-Recoupling hypothesis" of Behrenfeld (2010). The latter contradicts the common "Critical Depth hypothesis" by Sverdrup (1953) of vernal blooms. A sharp

565 decrease of the MLD was observed on average from September to October, followed by a chl-a decrease one month later, when the nutrients start reducing within the euphotic layer. This decreasing phase of the productive season corresponded exactly to a measurable cooling over the seamount, as observed from satellite SST from September to May (Fig. 9, solid light blue line, and Fig. S2) and confirmed by in situ CTD data in May 2017 (Fig. 6B). This cooling period precisely matches the seamount-specific enrichment phase (Fig. 9, solid blue line) that ends in June when the 
MLD was > 70-80 $\mathrm{m}$ again and associated with a minor (but still detectable) SST cooling (Fig. 9, light blue lines).

The spatio-temporal dynamics of the EI in the vicinity of the seamount (Fig. 8) highlights the way the upper part of the euphotic layer is enriched. The first detectable pattern occurs in September in a diffuse way around the Walters Shoal, as a possible consequence of the deep origin of the chl-a signal within the satellite penetration depth (20 m during this period, see dotted grey line on Fig. 9). It must be noted that such mesoscale "noise" associated with surface chl-a is omnipresent in the ocean and varies seasonally in space, mostly across latitudes (Brentnall et al., 2003).

The diffuse form of the enrichment persists in October, whereas the upper part of the seamount starts to be unambiguously enriched, sustaining high EI values up to May (Fig. 8, Fig. 9). These higher values probably originate from the whole penetration layer of the satellite observation. We have also seen that, from June to September (i.e., during the productive season), the central part of the Walters Shoal (depth $<200 \mathrm{~m}$ ) is less enriched than its surroundings (Fig. 8). This particular anomaly is likely a consequence of the topographic nature of the Walters Shoal summit (a caldera at approximately $50 \mathrm{~m}$ depth surrounded by several shallower summits, see Fig. 4 of Marsac et al., $2020 \mathrm{~b}$, this issue) that isolates an internal water mass from the surroundings. It is unlikely that this anomaly could be favoured by a Taylor cap structure during such a period of intense mixing,

590 because of the unstratified flow conditions that greatly reduce the vertical excursions of water parcels (and thus the likely presence of a Taylor cap structure) relative to the stratified flow conditions in summer (Chapman and Haidvogel, 1992).

As a consequence of this seasonal enrichment, the average chl-a concentration over the seamount

595 (plain green lines on Fig. 9) is almost constantly higher than at the surroundings (dotted green line on Fig. 9) from September to June. This produces a longer productive winter season over the seamount as well as a decrease in the seasonal amplitude of phytoplankton chl-a. Combined with the previously described negative anomaly (Fig. 4C), these two processes explain why a spatial minimum of chl-a variability is observed.

\subsection{Seamount comparisons}

A comparison of the EI seasonality together with the MLD, geostrophic current velocity and the cooling index is made for the Walters Shoal, MAD-Ridge and La Pérouse seamounts as well as

605 Tromelin Island. This reveals that none are comparable to the Walters Shoal in terms of surface enrichment (Fig. 10, solid dark blue lines), especially when the spatial averaging is carried out in the same way as described in the Methods, i.e. for distances $<30 \mathrm{~km}$ and in the range $60-90 \mathrm{~km}$ from the seamount/island centre. Due to their proximity, trends at the WS-2 seamount in the MLD, current and wind, are identical to those of the Walters Shoal (Fig. 10A). However, this is not the case with

610 the EI (not shown) which is less intense and limited to December - April, in exact synchrony with those observed at Walters Shoal. The much greater depth of the WS-2 seamount $(480 \mathrm{~m})$ is probably the only factor preventing a longer enrichment period to be detected within the upper part of the euphotic layer, suggesting a common enrichment mechanism. The MAD-Ridge seamount only shows slight winter cooling in June and July (Fig. 10B, solid light blue line) compared to its immediate 
615 surroundings (dashed light blue line). No enrichment structure is observed by satellite even on a monthly basis (Fig. S5). This could be due to the lacking of a Taylor cap, and the likelihood that any enrichment over the seamount would be swept away by the faster currents.

Despite moderate current speeds, the La Pérouse seamount (Fig. 10C) according to calculations, is

620 similarly unable to produce a Taylor cap. But as demonstrated by Koch-Larrouy et al. (2020, this issue) it is possible that internal waves generated from tidal currents are common. Even so, there are no signs of enrichment in the monthly climatological averages (Fig. 10C) nor from spatial monthly averages (Fig. S6). In situ data on the other hand does suggest enrichment. Three vertical profiles of chl-a measured over the upper part of the seamount during the La Pérouse cruise (Marsac et al.,

625 2020a, this issue) revealed DCM depths between 65 and $86 \mathrm{~m}$, whereas seven other profiles farther afield found DCMs situated between 80 and $130 \mathrm{~m}$ (data not shown). The DCMs measured on the seamount flanks were highly correlated with the nitracline depth $(\mathrm{r}=0.92 ; \mathrm{p}<0.05$; Marsac et al., 2020a), suggesting direct enrichment through the doming of the vertical structure, not associated with a Taylor cap in this case.

630

The tiny Tromelin Island (only $1 \mathrm{~km}$ long) whose average environment measured from the MLD, current speed, surface cooling and EI, is similar to that of the La Pérouse seamount, shows minor and seasonal enrichment (Fig. 10D, solid dark blue line) noticeable from September to March, with a peak in October. In this case, a spatial perspective of the EI (Fig. S7) reveals more precise patterns

635 in the form of systematic enrichment from September to May (increases from 6 to 12\%), centred over the seamount, without visible enrichment from June to August. Note to that, despite the fundamental topographic differences between island and seamount, the seasonality of the enrichment is similar to that observed at the Walters Shoal, suggesting a major influence of the seasonal stratification of the ocean in both cases, and despite the fact that a Taylor cap-induced

640 enrichment is not applicable to islands. As a conclusion, the proposed EI, when applied on daily chl-a fields, allows one to precisely discriminate episodic enrichment patterns (sometimes not visible through simple chl-a averages) in space and time, provided that seamount enrichment impacts the upper part of the euphotic layer detectable from space (about half of the MLD on average, from our observations).

\subsection{Vertical structure and seamount-induced changes in DCM (Walters Shoal)}

We have shown using seven vertical chl-a profiles measured during the Walters Shoal cruise, with matching MODIS data, that there is uplift (shallowing) of the DCM over the Walters Shoal (Fig. 5

650 and Fig. 6). We note a progressively more distinct maximum for the shallowest profiles, with a maximum $<35 \mathrm{~m}$. Such changes have been previously reported for other deep seamounts. For instance, at the Minami-kasuga Seamount (northwest Pacific, $260 \mathrm{~m}$ minimum depth), Genin and Boehlert (1985) showed that thermocline structure was simultaneously compressed and uplifted in the vicinity of the seamount. Similar changes were observed by Dower et al. (1992) over the

655 shallow Cobb seamount in the northeastern Pacific, one of the few similar shallow seamounts explored with a summit at $24 \mathrm{~m}$. Here the DCM was found at an average depth of $50 \mathrm{~m}$. It is also likely that the phytoplankton biomass over the Cobb seamount was greater than suggested from the in situ chl-a measurements, owing to a decrease of the chlorophyll:carbon ratio which is generally 
observed where phytoplankton is upwelled at higher light regimes (Dower et al., 1992; Geider et al., 1997).

At the Walters Shoal, the average SST during the same period (Fig. 6B, insert) shows a well pronounced cold dome attributable to the uplifting (shoaling) of isotherms, centred over the southern flank of the seamount, with a surface cooling of approximately $1.0^{\circ} \mathrm{C}$ relative to the surroundings. It is likely that the centre of the cold dome was even closer to the flat summit which was not sampled due to the very shallow bathymetry. The average cooling index previously computed from satellite data over the entire period 2003-2018 (Fig. 7D and Fig. S3) shows a similar pattern, with a spatial maximum similarly centred on the southern part of the seamount.

670 The grouping of chlorophyll profiles at three distances from the seamount (described in Section 3.1.2, Fig. 6B) highlight a progressive shoaling of the phytoplankton structure from the $500 \mathrm{~m}$ isobaths to the summit. Accordingly, the DCM shallows from $80-100 \mathrm{~m}$ to $<50 \mathrm{~m}$. This pattern is similar to that found by Dower et al. (1992) and Comeau et al. (1995) over the Cobb Seamount (24 m) were an average integrated value of $15 \pm 2 \mathrm{mg} \mathrm{m}^{-2}$ has been observed. Interestingly, we did not

675 find (see Table 1) a significant increase of the integrated chl-a at the seamount compared to the offshore stations, while a ratio of 3.5 was observed at the Cobb Seamount (Comeau et al. 1995) with distant stations situated in a purely oligotrophic environment. It is surprising that we did not find such a ratio at the Walters Shoal, especially since Odate and Furuya (1998) found a ratio of $\sim 2$ over much deeper seamounts at the Komahashi No. 2 seamount $(289 \mathrm{~m})$, with similar vertical movements of the DCM (from 70-90 $\mathrm{m}$ up to 40-50 m). A possible reason for this is the lack of distant stations in an oligotrophic environment during our cruise.

It is worth noting however, that the abundance of all four taxonomic groups found at the Walters Shoal (i.e., small flagellates, prokaryotes, diatoms and dinoflagellates) was influenced, to different

685 degrees, by the presence of the seamount (see Table 2 and results in Section 3.1.2). We used the same partitioning as for the three types of chl-a profiles. Whereas small flagellates and prokaryotes dominated all stations (92\% on average), the relative proportion of diatoms near the seamount (relative to the farthest stations) was 50\% higher in the surface layer and $83 \%$ higher in the DCM. This suggests that diatoms were directly favored by environmental conditions (mostly nitrates and 690 silicates) associated with the shallowing of the DCM. Similar results have been described by Mouriño et al. (2001) at the Great Meteor Tablemount $\left(30.0^{\circ} \mathrm{N}\right)$ in the northeast Atlantic where "small flagellates were the dominant group in terms of biomass" for three different cruises. Also diatom biomass was "significantly higher at the central region of the GMT". Comeau et al. (1995) similarly observed shifts in community structure towards diatoms at the Cobb Seamount, especially 695 "at stations with stronger subsurface chlorophyll $a$ maxima", as we observed at the Walters Shoal. Small flagellates are dominant at the DCM whereas prokaryotes dominate the nutrient-depleted surface waters where this group has a strong competitive advantage. This later is reduced at the seamount stations where prokaryotes are $40 \%$ less abundant than at stations farther away, and this is consistent with the fact that nitrates are not depleted at these stations, as previously shown.

However, our results contrast with those of Sonnekus et al. (2017) for an unnamed seamount (1255 $\mathrm{m})$ found north of the Walters Shoal $\left(31^{\circ} 34.33^{\prime} \mathrm{S}\right.$; $\left.42^{\circ} 45.78^{\prime} \mathrm{E}\right)$ can be associated with oligotrophic 
conditions in our case), who found a dominance of diatoms and dinoflagellates (in approximately equal proportion) in all seamounts explored in the SWIO, because small flagellates have been strongly underestimated due to an unadequate sample conservation method used (Sonnekus et al. 2017).

Overall, our results demonstrate that the Walters Shoal seamount has a spatial influence on the phytoplankton community composition, which in turn is related to vertical changes in the DCM and nutrient concentrations (limitations).

\subsection{Primary production estimates}

We estimated the primary production (PP) and its change under varying light conditions, related to a shallowing of the DCM due to the proximity of the seamount. Whereas the integrated chl-a across all stations was remarkably stable, the estimated PP (Table 1) in contrast was enhanced by the shallowing of the DCM. This resulted in a PP of $0.70 \mathrm{gC} \mathrm{m}^{-2}$ day $^{-1}$ at the most distant stations, 0.87 $\mathrm{gC} \mathrm{m}^{-2}$ day $^{-1}$ for the intermediate ones $(+23 \%)$ and $1.49 \mathrm{gC} \mathrm{m}^{-2}$ day $^{-1}$ (i.e., $+113 \%$ ) for the central stations over the seamount. Although it is likely that the production to biomass ratio (not measured during the cruise) varies over the seamount due to changing light conditions which in turn are regulated by the DCM (Genin and Boehlert, 1985), this ratio also increases because of the simultaneous nutrient supply (Spilling et al., 2015). This probably explains why a greater proportion of diatoms, measured using the HPLC, were observed over the Walters Shoal seamount (see previous section).

It is clear that the chl-a increase represented by our EI over the Walters Shoal seamount is a consequence of a nutrient supply close to the surface, where the signal integrated by the satellite sensor originates (a depth of 30-50 m according to the average chl-a values in common oligotrophic environments). Consequently, an "enrichment index" measured from space, even not necessarily

730 associated with a biomass increase in the whole euphotic layer (even if that is generally the case) could be considered as an indicator of a possible increase in PP. This hypothesis is reinforced by the fact that nutrients were not fully depleted at several stations near the seamount, potentially favouring primary production.

735 Our EI is associated to a chl-a increase of $40 \%$ over the seamount, with an estimated doubling in PP when considering the shape of the chl-a profile. As summarized by Pitcher and Bulman (2007), enhancement of primary production by $5-10 \%$ over seamounts has been shown by several authors (Dower et al., 1992; Odate and Furuya, 1998; Mouriño et al., 2001), but at very shallow seamounts (such as the Cobb Seamount) the increase might be as much as $60 \%$. That is almost a doubling of

740 the primary production, as similarly suggested at the Walters Shoal seamount from our own calculation.

\section{Conclusions}


We studied potential topographic-induced chlorophyll enrichment at three shallow seamounts (Walters Shoal, MAD-Ridge, La Pérouse) and one island (Tromelin Island) in the SWIO using a combination of satellite observations and cruise data. These sites varied in latitude between 15 and $33^{\circ} \mathrm{S}$ (a longitudinal distance some $1100 \mathrm{~nm}$ ), with varied contrasting environments (also see Vianello et al., this issue).

In the scale of the SWIO, these features are tiny and any local effects are hard to see at times in standard resolution $4 \mathrm{~km} \mathrm{L3}$ satellite SST and chl-a data products. Certainly the standard approach of using averages conceals any local signals especially if seasonal. To overcome this problem, we

755 have developed a new method (algorithm) of enhancing these localised, transient surface signals. With reference to surrounding pixels between radii of 30 and $90 \mathrm{~km}$ away, we introduce a chl-a based enrichment index (EI) and SST cooling index, and use these to successfully delineate the spatial and temporal characteristics of seamount and small island effects in the SWIO, with specific focus on the four identified sites.

Of the four sites, the Walters Shoal $(18 \mathrm{~m})$ had the most stark localised surface enrichment and cooling. We find that the recurrent uplifting of isotherms over the shallow seamount has a sustainable effect of increasing primary production. This is measured up to $50 \mathrm{~km}$ from the seamount centre over depths $<500 \mathrm{~m}$ for most of the year. Despite the fact that the Walters Shoal cruise took place during an intermediate season with enrichment far from the seasonal maximum, we further find a clear correlation between in situ measurements and chl-a determined by satellite - reaffirming our confidence in the enrichment algorithm. We also observe that geostrophic currents (satellite-determined) are noticeably reduced in the vicinity of the seamount, lending credence to the possible existence of a Taylor cap here. Diagnostic pigments from in situ samples

770 analysed by HPLC, indicate diatoms and small flagellates to increase towards the seamount where nutrients are not depleted. Importantly, the use of satellite observations enabled us to precisely describe the seasonality of this enrichment, a trait not possible from a research cruise.

Our analysis also shows that local surface enrichment is not exclusive to shallow seamounts. A 775 distinct and much deeper $(480 \mathrm{~m})$ volcano situated 100 nautical miles southeast of the Walters (referred to as WS-2) also produces chl-a increases visible from space. This is surprisingly much more than the narrow La Pérouse Seamount with a summit considerably shallower $(60 \mathrm{~m})$. Given the depth of the WS-2, it is interesting too that the MAD-Ridge seamount (240 m), a strong focus of the MADRidge project (see Roberts et al. this issue), has no discernible enrichment signal. This

780 conical-shaped seamount is located in a region of high KE (eddies) and consequently fast currents, which certainly prevent Taylor cap formation most of the time, and therefore quickly sweep away any enrichment. A situation completely opposite to the Walters Shoal.

A far reaching implication of our Walters Shoal seamount observations concerns the energy transfer 785 from primary producers to higher trophic levels. From the Walters Shoal cruise, zooplankton biomass was found to be low relative to that found at other seamounts (Noyon et al., 2020, this issue). To account for this, those authors suggested that the large scale environment had more impact on the zooplankton community at seamounts rather than the intrinsic seamount processes themselves. Consequently, given the short time span of sampling during cruises, it is usually 
790 difficult to find the link between primary production at the seamount and higher trophic levels, i.e. increased phytoplankton biomass=increased zooplankton biomass. Our study on the other hand, showed that most of the locally produced chl-a was advected away from the Walters Shoal seamount by the (geostrophic) current field, thus enhancing productivity more at the surrounding than the summit area. Benefits for secondary productivity would therefore not be seen at the Walters Shoal. This would account for the findings by Noyon et al. (this issue).

Finally, in a regional perspective, it is clear that shallow seamounts in the SWIO occupy a tiny fraction of the surface area, and produce a small fraction of the total productivity - the exception here being the Mascarene Plateau. Even so, in a mostly oligotrophic setting, at a local scale they are

800 a significant source of primary productivity and consequently biodiversity hotspots which no doubt play important roles in aggregating local and distant species, and increasing regional connectivity.

\section{Disclaimer}

805

This article is a research paper. The views expressed by the authors do not necessarily reflect those of their affiliated institutions. The designations employed do not imply the expression of any opinion whatsoever on the part of affiliated institutions concerning the legal status of any country, territory, or area or of its authorities, or concerning the delimitation of its frontiers or boundaries.

810 The presentation of material prejudges no support for claiming States.

\section{Acknowledgements}

We thank the officers and crew of the RV Marion Dufresne II, who undertook cruise MD208 as part

815 of the FFEM-SWIO project on Areas Beyond National Jurisdiction (ABNJ) in the South West Indian Ocean. This was funded by the Fonds Français pour l'Environnement Mondial (FFEM) and coordinated by the IUCN. MD208 was facilitated by the Institut Polaire IPEV, France. The work was supported financially and logistically by the Institut de Recherche pour le Développement (IRD) and the Flotte Océanographique Française. We also thank F. Baurand and S. Hillion (IRD,

820 Brest) for performing the chemical analyses (nutrients and phytoplankton pigments) presented herein and the officers, crew and scientists of the RV Antea for their assistance during the three shallow seamount research cruises. Finally, we are extremely grateful to the three reviewers for their critical comments and useful suggestions that allowed us to consolidate the paper and greatly improve the quality of the initial manuscript. 


\section{References}

Arístegui, J., Mendonça, A., Vilas, J.C., Espino, M., Polo, I., Montero, M.F., Martins, A., 2009. Plankton metabolic balance at two North Atlantic seamounts, In: B. Christensen and G. Wolff (eds). The Oceanography, Biogeochemistry and Ecology of Two NE Atlantic Seamounts: OASIS. Deep Sea Res. Part II Top. Stud. Oceanogr. 56, 2646-2655. https://doi.org/10.1016/j.dsr2.2008.12.025

Barlow, R., Lamont, T., Kyewalyanga, M., Sessions, H., Morris, T. 2010. Phytoplankton production and physiological adaptation on the southeastern shelf of the Agulhas ecosystem. Continent. Shelf Res. 30(13), 1472-1486. https://doi.org/10.1016/j.csr.2010.05.007.

Beckmann, A., Mohn, C., 2002. The upper ocean circulation at Great Meteor Seamount. Part II: Retention potential of the seamount induced circulation. Ocean Dyn. 52, 194-202. https://doi.org/10.1007/s10236-002-0018-3

Behrenfeld, M.J., 2010. Abandoning Sverdrup's critical depth hypothesis on phytoplankton blooms. Ecology 91, 977-989. https://doi.org/10.1890/09-1207.1

Behrenfeld, M.J., Falkowski, P., 1997. Photosynthetic rates derived from satellite-based chlorophyll concentration. Limnol. Oceanogr. 42, 1-20. https://doi.org/10.4319/lo.1997.42.1.0001

Boehlert, G.W., Genin, A., 1987. A review of the effects of seamounts on biological processes, In: Seamounts, Islands, and Atolls. American Geophysical Union (AGU), pp. 319-334. https://doi.org/10.1029/GM043p0319

Brentnall, S.J., Richards, K.J., Brindley, J., Murphy, E., 2003. Plankton patchiness and its effect on larger-scale productivity. J. Plankton Res. 25, 121-140. https://doi.org/10.1093/plankt/25.2.121

Brink, K.H., 1989. The effect of stratification on seamount-trapped waves. Deep Sea Res. Part A Oceanogr. Res. Pap. 36, 825-844. https://doi.org/10.1016/0198-0149(89)90031-9

Chaigneau, A., Texier, M.L., Eldin, G., Grados, C., Pizarro, O., 2011. Vertical structure of mesoscale eddies in the eastern South Pacific Ocean: a composite analysis from altimetry and Argo profiling floats. J. Geophys. Res. 116, 16 pp. https://doi.org/201110.1029/2011JC007134

Chapman, D.C., Haidvogel, D.B., 1992. Formation of Taylor caps over a tall isolated seamount in a stratified ocean. Geophys. Astrophys. Fluid Dyn. 64, 31-65. https://doi.org/10.1080/03091929208228084

Clark, M.R., Vinnichenko, V.I., Gordon, J.D.M., Beck $\square$ Bulat, G.Z., Kukharev, N.N., Kakora, A.F., 2008. Large-scale distant-water trawl fisheries on seamounts, In: Seamounts: Ecology, Fisheries \& Conservation. John Wiley \& Sons, Ltd, pp. 361-399. https://doi.org/10.1002/9780470691953.ch17

Clark, M.R., Rowden, A.A., Schlacher, T., Williams, A., Consalvey, M., Stocks, K.I., Rogers, A.D., O'Hara, T.D., White, M., Shank, T.M., Hall-Spencer, J.M., 2010. The Ecology of Seamounts: Structure, Function, and Human Impacts. A. Rev. Mar. Sci. 2, 253-278. https://doi.org/10.1146/annurev-marine-120308-081109

Comeau, L.A., Vézina, A.F., Bourgeois, M., Juniper, S.K., 1995. Relationship between phytoplankton production and the physical structure of the water column near Cobb Seamount, northeast Pacific. Deep Sea Res. Part I. Oceanogr. Res. Pap. 42, 993-1005. https://doi.org/10.1016/0967-0637(95)00050-G

de Boyer Montégut, C., Madec, G., Fischer, A.S., Lazar, A., Iudicone, D., 2004. Mixed layer depth over the global ocean: an examination of profile data and a profile-based climatology. J. Geophys. Res. 109, C12003. https://doi.org/10.1029/2004JC002378

Demarcq, H. 2009. Trends in Primary Production, Sea Surface Temperature and Wind in Upwelling Systems (1998-2007). Progress in Oceanogr., Eastern Boundary Upwelling Ecosystems Symposium: Integrative and Comparative Approaches, 2-8 June 2008, Las Palmas, Gran Canaria, Spain, 83 (1-4): 376-85. https://doi.org/10.1016/j.pocean.2009.07.022. 
Denda, A., Stefanowitsch, B., Christiansen, B., 2017. From the epipelagic zone to the abyss: trophic structure at two seamounts in the subtropical and tropical Eastern Atlantic - Part I zooplankton and micronekton. Deep Sea Res. Part I. Oceanogr. Res. Pap. 130, 63-77. https://doi.org/10.1016/j.dsr.2017.10.010

Dower, J., Freeland, H., Juniper, K., 1992. A strong biological response to oceanic flow past Cobb Seamount. Deep Sea Res. Part A. Oceanogr. Res. Pap. 39, 1139-1145. https://doi.org/10.1016/0198-0149(92)90061-W

Fock, H.O., 2012. Seamounts: Ecology, Fisheries \& Conservation. Fish Fish. 13, 238-239. https://doi.org/10.1111/j.1467-2979.2012.00458.x

Frouin, R., McPherson, J., Ueyoshi, K., Franz, B.A., 2012. A time series of photosynthetically available radiation at the ocean surface from SeaWiFS and MODIS data. Presented at the Remote Sensing of the Marine Environment II, International Society for Optics and Photonics, p. 852519. https://doi.org/10.1117/12.981264

Geider, R., MacIntyre, H., Kana, T., 1997. Dynamic model of phytoplankton growth and acclimation: responses of the balanced growth rate and the chlorophyll a:carbon ratio to light, nutrient-limitation and temperature. Mar. Ecol. Prog. Ser. 148, 187-200. www.jstor.org/stable/24857483. https://doi.org/10.3354/meps148187

Genin, A., 2004. Bio-physical coupling in the formation of zooplankton and fish aggregations over abrupt topographies. J. Mar. Syst. 50, 3-20. https://doi.org/10.1016/j.jmarsys.2003.10.008

Genin, A., Boehlert, G.W., 1985. Dynamics of temperature and chlorophyll structures above a seamount: an oceanic experiment . https://doi.org/10.1357/002224085788453868

Genin, A., Dower, J.F., 2007. Seamount plankton dynamics, In: Seamounts: Ecology, Fisheries \& Conservation. John Wiley \& Sons, Ltd, pp. 87-100. https://doi.org/10.1002/9780470691953.ch5

Goldner, D.R., Chapman, D.C., 1997. Flow and particle motion induced above a tall seamount by steady and tidal background currents. Deep Sea Res. Part I. Oceanogr. Res. Pap. 44, 719744. https://doi.org/10.1016/S0967-0637(96)00131-8

Gordon, H.R., Morel, A.Y., 1983. Remote assessment of ocean color for interpretation of satellite visible imagery: a review. Lecture Notes on Coastal and Ocean Studies, 4. Springer. https://doi.org/10.1007/978-1-4684-6280-7

Hunkins, K., 1986. Anomalous diurnal tidal currents on the Yermak Plateau. J. Mar. Res. 44, 51-69.

Huppert, H.E., 1975. Some remarks on the initiation of inertial Taylor columns. J. Fluid Mech. 67, 397-412. https://doi.org/10.1017/S0022112075000377

Keating, B.H., Fryer, P., Batiza, R., Boehlert, G.W., 1987. Seamounts, islands, and atolls. Am. Geophys. Union Geophys. Monogr. Ser. 43. https://doi.org/10.1029/GM043

Kitchingman, A., Lai, S., Morato, T., Pauly, D., 2007. How many seamounts are there and where are they located? In: Seamounts: Ecology, Fisheries \& Conservation. John Wiley \& Sons, Ltd, pp. 26-40. https://doi.org/10.1002/9780470691953.ch2

Koch-Larrouy, A., Ternon, J.F., Roberts, M., Chanut, J., Lyard, F., Bourdalle-Badié, R., Ansong, J.K., Arbic, B.K., Tchilibou, M., Buijsman, M.C., Vianello, P., Allain, D., Herbette, S., Demarcq, H., Shriver, J.F., 2020. Exploring mixing above a group of seamounts of the northern Madagascar Ridge, and their possible impact on algae blooms. Deep Sea Res. Part II (this issue)

Kunze, E., Sanford, T.B., 1996. Abyssal mixing: where it is not. J. Phys. Oceanogr. 26, 2286-2296. https://doi.org/10.1175/1520-0485

Lemos, A.T., Ghisolfi, R.D.R., Mazzini, P.L.F., 2018. Annual phytoplankton blooming using satellite-derived chlorophyll-a data around the Vitória-Trindade Chain, Southeastern Brazil. Deep Sea Res. Part I. Oceanogr. Res. Pap. 136, 62-71.

https://doi.org/10.1016/j.dsr.2018.04.005 
Lutjeharms, J. R. E., Bang, N. D., Duncan, C. P., 1981. Characteristics of the Currents East and South of Madagascar. Deep Sea Res. Part A. Oceanographic Research Papers 28 (9): 87999. https://doi.org/10.1016/0198-0149(81)90008-X.

Marsac, F., Annasawmy, P., Noyon, M., Demarcq, H., Soria, M., Rabearisoa, N., Bach, P., Cherel, Y, Grelet, J., Romanov, E.V., 2020a. Physical environment and ecological interactions at and near La Pérouse seamount, northwest of Reunion Island, Indian Ocean. Deep Sea Res. Part II. (this issue)

Marsac, F., Galletti, F., Ternon, J-F., Romanov, E.V., Demarcq, H., Corbari, L., Bouchet, P., Roest, W.R., Jorry, S.J., Olu, K., Loncke, L., Roberts, M.J., Ménard, F., 2020b. Seamounts, plateaus and governance issues in the southwestern Indian Ocean, with emphasis on fisheries management and marine conservation, using the Walters Shoal as a case study for implementing a protection framework. Deep Sea Res. Part II. (this issue)

Miller, K.J., Gunasekera, R.M., 2017. A comparison of genetic connectivity in two deep sea corals to examine whether seamounts are isolated islands or stepping stones for dispersal. Sci. Rep. 7, 1-14. https://doi.org/10.1038/srep46103

Mohn, C., Beckmann, A., 2002. The upper ocean circulation at Great Meteor Seamount. Part I: Structure of density and flow fields. Ocean Dyn. 52, 179-193. https://doi.org/10.1007/s10236-002-0017-4

Morel, A., Maritorena, S., 2001. Bio-optical properties of oceanic waters: a reappraisal. J. Geophys. Res. Oceans 106, 7163-7180. https://doi.org/10.1029/2000JC000319

Mouriño, B., Fernandez, E., Serret, P., Harbour, D., Sinha, B., Pingree, R., 2001. Variability and seasonality of physical and biological fields at the Great Meteor Tablemount (subtropical NE Atlantic). Oceanol. Acta 24, 167-185. https://doi.org/doi:10.1016/S0399-1784

Nauw, J.J., van Aken, H.M., Webb, A., Lutjeharms, J.R.E., de Ruijter, W.P.M., 2008. Observations of the southern East Madagascar Current and undercurrent and countercurrent system. J. Geophys. Res. Oceans 113. https://doi.org/10.1029/2007JC004639

Noyon, M., Rasoloarijao, Z., Huggett, J., Ternon, J-F., Roberts, M., 2020. Comparison of mesozooplankton communities at three shallow seamounts in the South West Indian Ocean. Deep Sea Res. Part II. (this issue)

Odate, T., Furuya, K., 1998. Well-developed subsurface chlorophyll maximum near Komahashi No. 2 seamount in the summer of 1991. Deep Sea Res. Part I. Oceanogr. Res. Pap. 45, 15951607. https://doi.org/10.1016/S0967-0637(98)00031-4

Oliveira, A.P., Coutinho, T.P., Cabeçadas, G., Brogueira, M.J., Coca, J., Ramos, M., Calado, G., Duarte, P., 2016. Primary production enhancement in a shallow seamount (Gorringe Northeast Atlantic). J. Mar. Syst. https://doi.org/10.1016/j.jmarsys.2016.07.012

Pitcher, T.J., Bulman, C., 2007. Raiding the larder: a quantitative evaluation framework and trophic signature for seamount food webs, In: Seamounts: Ecology, Fisheries \& Conservation. John Wiley \& Sons, Ltd, pp. 282-295. https://doi.org/10.1002/9780470691953.ch14

Read, J., Pollard, R., 2017. An introduction to the physical oceanography of six seamounts in the southwest Indian Ocean, In: The Pelagic Ecology of Seamounts of the South West Indian Ocean. Deep Sea Res. Part II Top. Stud. Oceanogr., 136, 44-58. https://doi.org/10.1016/j.dsr2.2015.06.022

Roberts, M., Ternon, J.F., Marsac, F., Noyon, M., 2020. The MADRidge Project: Bio-Physical coupling around three shallow seamounts of the Southwest Indian Ocean (this issue)

Roden, G.I., 2013. Effect of seamounts and seamount chains on ocean circulation and thermohaline structure, In: Seamounts, Islands, and Atolls. American Geophysical Union (AGU), pp. 335354. https://doi.org/10.1029/GM043p0335

Rogers, A., 2012. An ecosystem approach to management of seamounts in the southern Indian Ocean. 1: Overview of seamount ecosystems and biodiversity. IUCN, Gland, Switzerland, $18 \mathrm{pp}$. 
Rogers, A.D., 1994. The biology of seamounts, In: Blaxter, J.H.S., Southward, A.J. (Eds), Advances in Marine Biology. Academic Press, pp. 305-350. https://doi.org/10.1016/S00652881(08)60065-6

Rogers, A.D., 2018. The biology of seamounts: 25 years on, In: Sheppard, C. (Ed.), Advances in Marine Biology. Academic Press, pp. 137-224. https://doi.org/10.1016/bs.amb.2018.06.001

Rogers, A.D., Alvheim, O., Bemanaja, E., Benivary, D., Boersch-Supan, P., Bornman, T.G., Cedras, R., Du Plessis, N., Gotheil, S., Høines, A., Kemp, K., Kristiansen, J., Letessier, T., Mangar, V., Mazungula, N., Mørk, T., Pinet, P., Pollard, R., Read, J., Sonnekus, T., 2017. Pelagic communities of the South West Indian Ocean seamounts: R/V Dr Fridtjof Nansen Cruise 2009-410, In: The Pelagic Ecology of Seamounts of the South West Indian Ocean. Deep Sea Res. Part II Top. Stud. Oceanogr., 136, 5-35. https://doi.org/10.1016/j.dsr2.2016.12.010

Rowden, A.A., Dower, J.F., Schlacher, T.A., Consalvey, M., Clark, M.R., 2010. Paradigms in seamount ecology: fact, fiction and future. Mar. Ecol. 31, 226-241. https://doi.org/10.1111/j.1439-0485.2010.00400.x

Samadi, S., Bottan, L., Macpherson, E., De Forges, B.R., Boisselier, M-C., 2006. Seamount endemism questioned by the geographic distribution and population genetic structure of marine invertebrates. Mar. Biol. 149, 1463-1475. https://doi.org/10.1007/s00227-006-03064

Shank, T., 2010. Seamounts: deep-ocean laboratories of faunal connectivity, evolution, and endemism. Oceanography 23, 108-122. https://doi.org/10.5670/oceanog.2010.65

Simmons, H.L., Hallberg, R.W., Arbic, B.K., 2004. Internal wave generation in a global baroclinic tide model, In: Small and Mesoscale Processes and their Impact on the Large Scale. Deep Sea Res. Part II Top. Stud. Oceanogr., 51, 3043-3068. https://doi.org/10.1016/j.dsr2.2004.09.015

Sonnekus, M.J., Bornman, T.G., Campbell, E.E., 2017. Phytoplankton and nutrient dynamics of six South West Indian Ocean seamounts. Deep Sea Res. Part II Top. Stud. Oceanogr., The Pelagic Ecology of Seamounts of the South West Indian Ocean 136, 59-72. https://doi.org/10.1016/j.dsr2.2016.12.008

Spilling, K., Ylöstalo, P., Simis, S., Seppälä, J., 2015. Interaction effects of light, temperature and nutrient limitations ( $\mathrm{N}, \mathrm{P}$ and $\mathrm{Si}$ ) on growth, stoichiometry and photosynthetic parameters of the cold-water diatom Chaetoceros wighamii. PLoS ONE 10. https://doi.org/10.1371/journal.pone.0126308

Sverdrup, H.U., 1953. On conditions for the vernal blooming of phytoplankton. J. Cons. 18, 287295. https://doi.org/10.1093/icesjms/18.3.287

Toole, J.M., Schmitt, R.W., Polzin, K.L., Kunze, E., 1997. Near-boundary mixing above the flanks of a midlatitude seamount. J. Geophys. Res. 102, 947-959. https://doi.org/10.1029/96JC03160

Vianello, J.F., Herbette, P., Ternon, S., Demarcq, H., Roberts, M.J., 2020. Ocean currents and environmental gradients in the vicinity of the Madagascar Ridge in the Southwest Indian Ocean. Deep Sea Res. Part II. (this issue)

Werdell, P.J., Bailey, S.W., 2005. An improved in-situ bio-optical data set for ocean color algorithm development and satellite data product validation. Remote Sens. Environ. 98, 122-140. https://doi.org/10.1016/j.rse.2005.07.001

White, M., Bashmachnikov, I., Arístegui, J., Martins, A., 2007. Physical processes and seamount productivity, In: Seamounts: Ecology, Fisheries \& Conservation. John Wiley \& Sons, Ltd, pp. 62-84. https://doi.org/10.1002/9780470691953.ch4

Yesson, C., Clark, M.R., Taylor, M.L., Rogers, A.D., 2011. The global distribution of seamounts based on 30 arc seconds bathymetry data. Deep Sea Res. Part I Oceanogr. Res. Pap. 58, 442-453. https://doi.org/10.1016/j.dsr.2011.02.004 
Journal Pre-proof

\begin{tabular}{cccccccc}
\hline & $\mathrm{n}$ & $\begin{array}{c}\text { Zdcm } \\
(\mathrm{m})\end{array}$ & $r m s$ & $\begin{array}{c}\text { Int. Chl-a } \\
\left(\mathrm{mg} \mathrm{m}^{-2}\right)\end{array}$ & $r m s$ & $\begin{array}{c}\text { Int. PP } \\
\left(\mathrm{gC} \mathrm{m}^{-2} \text { day }^{-1}\right)\end{array}$ & $r m s$ \\
\hline Outside & $\mathbf{4}$ & $\mathbf{7 9 . 8}$ & 3.3 & $\mathbf{2 6 . 3}$ & 4.9 & $\mathbf{0 . 7 0}$ & 0.1 \\
\hline Intermediate & $\mathbf{7}$ & $\mathbf{4 9 . 6}$ & 10.2 & $\mathbf{2 1 . 3}$ & 4.0 & $\mathbf{0 . 8 7}$ & 0.3 \\
\% increase & & & & $-19 \%$ & & $+23.5 \%$ & \\
\hline Seamount & $\mathbf{1 1}$ & $\mathbf{3 2 . 6}$ & 9.4 & $\mathbf{2 6 . 0}$ & 6.7 & $\mathbf{1 . 4 9}$ & 0.3
\end{tabular}




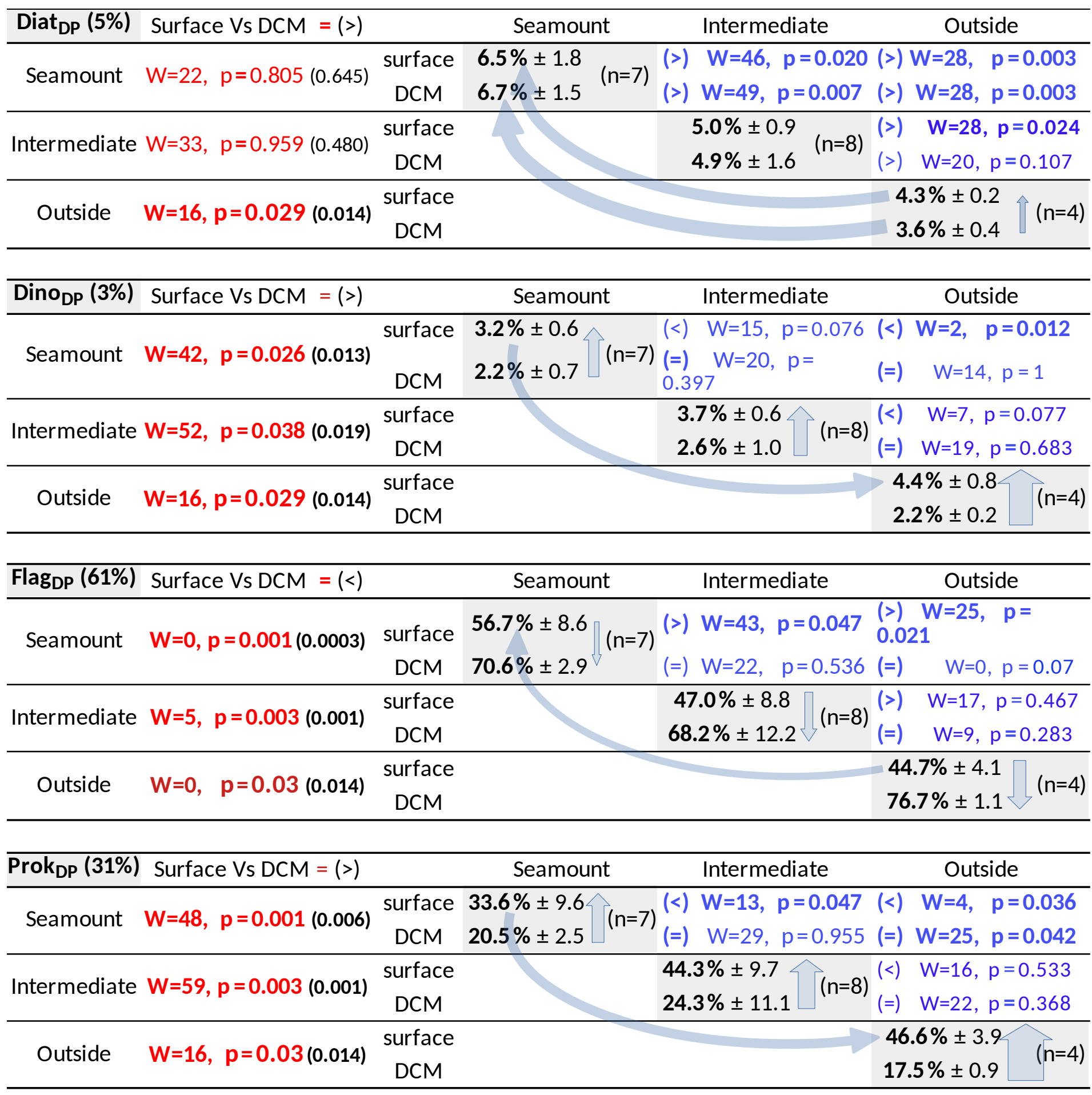


Table 1.

\begin{tabular}{|c|c|c|c|c|c|c|c|}
\hline & $\mathrm{n}$ & $\begin{array}{l}\text { Zdcm } \\
(\mathrm{m})\end{array}$ & $r m s$ & $\begin{array}{l}\text { Int. Chl-a } \\
\left(\mathrm{mg} \mathrm{m}^{-2}\right)\end{array}$ & $r m s$ & $\begin{array}{c}\text { Int. PP } \\
\left(\mathrm{gC}^{-2} \text { day }^{-1}\right)\end{array}$ & rms \\
\hline Outside & 4 & 79.8 & 3.3 & 26.3 & 4.9 & 0.70 & 0.1 \\
\hline Intermediate & 7 & 49.6 & 10.2 & 21.3 & 4.0 & 0.87 & 0.3 \\
\hline$\%$ increase & & & & $-19 \%$ & & $+23.5 \%$ & \\
\hline Seamount & 11 & 32.6 & 9.4 & 26.0 & 6.7 & 1.49 & 0.3 \\
\hline$\%$ increase & & & & $-1 \%$ & & $113 \%$ & \\
\hline
\end{tabular}


Table 2.

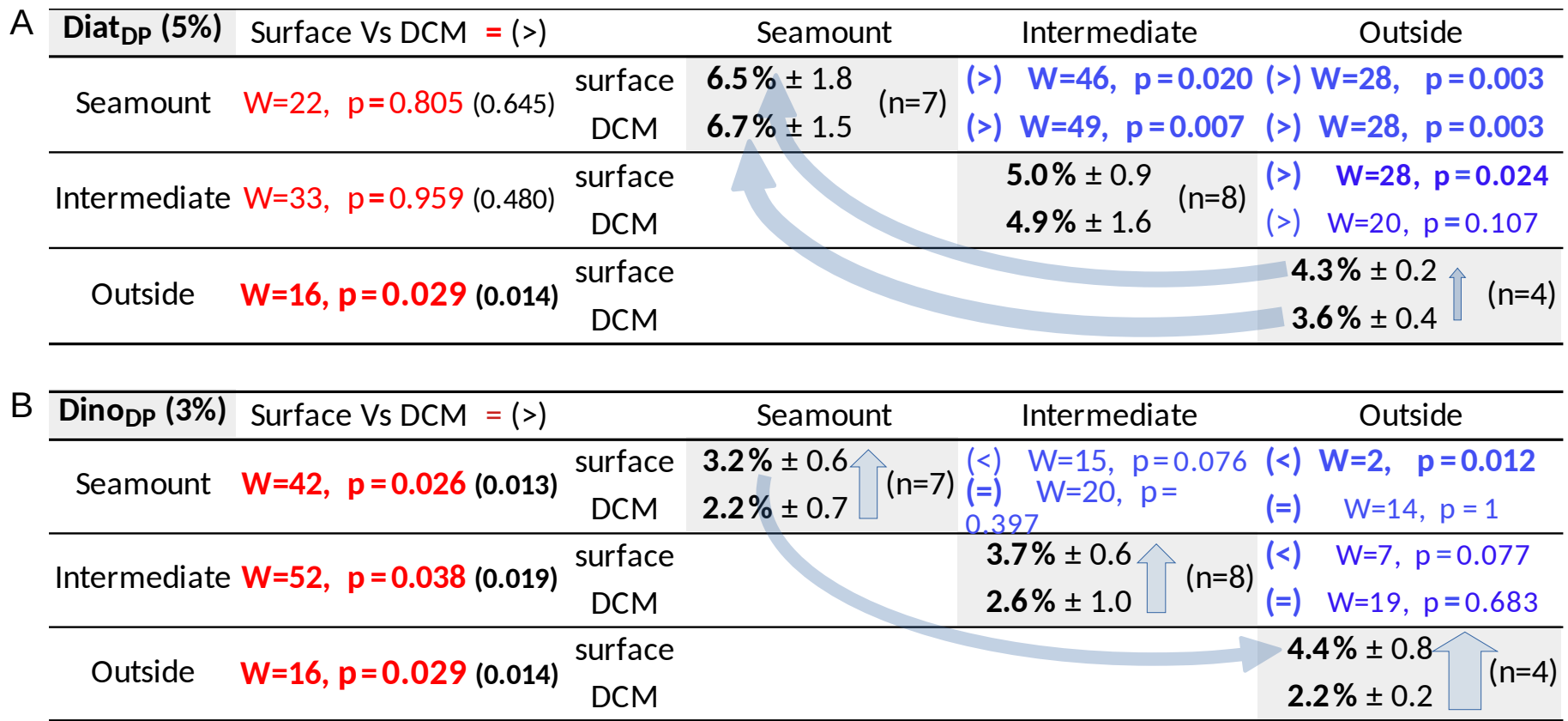

\begin{tabular}{|c|c|c|c|c|c|}
\hline Flag $_{\mathrm{DP}}(61 \%)$ & Surface Vs DCM $=(<)$ & & Seamount & Intermediate & Outside \\
\hline Seamount & $W=0, p=0.001(0.0003)$ & $\begin{array}{l}\text { surface } \\
\text { DCM }\end{array}$ & $\begin{array}{l}56.7 \% \pm 8.6 \\
70.6 \% \pm 2.9\end{array}(n=7)$ & $\begin{array}{l}(>) \mathrm{W}=43, \mathrm{p}=0.047 \\
\Leftrightarrow) \mathrm{W}=22, \mathrm{p}=0.536\end{array}$ & $\begin{array}{l}0.021 \\
(=) \quad W=0, p=0.07\end{array}$ \\
\hline Intermediate & $W=5, p=0.003(0.001)$ & $\begin{array}{l}\text { surface } \\
\text { DCM }\end{array}$ & & $\begin{array}{c}47.0 \% \pm 8.8 \\
68.2 \% \pm 12.2\end{array} \quad(n=8)$ & $\begin{array}{ll}\Leftrightarrow & W=17, p=0.467 \\
\Leftrightarrow & W=9, p=0.283\end{array}$ \\
\hline Outside & $W=0, \quad p=0.03(0.014)$ & $\begin{array}{l}\text { surface } \\
\text { DCM }\end{array}$ & & & $\begin{array}{l}44.7 \% \pm 4.1 \\
76.7 \% \pm 1.1\end{array} \quad(n=4$ \\
\hline
\end{tabular}

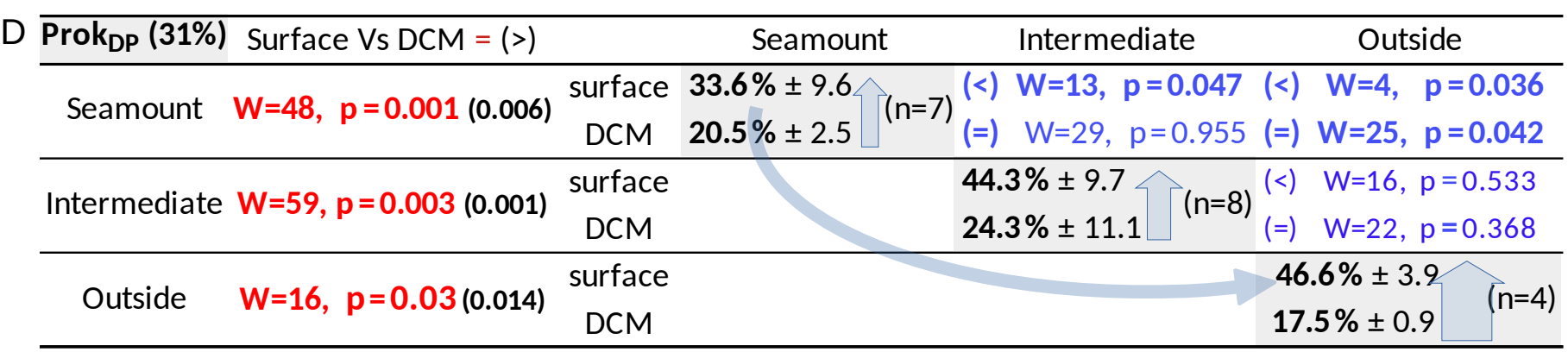




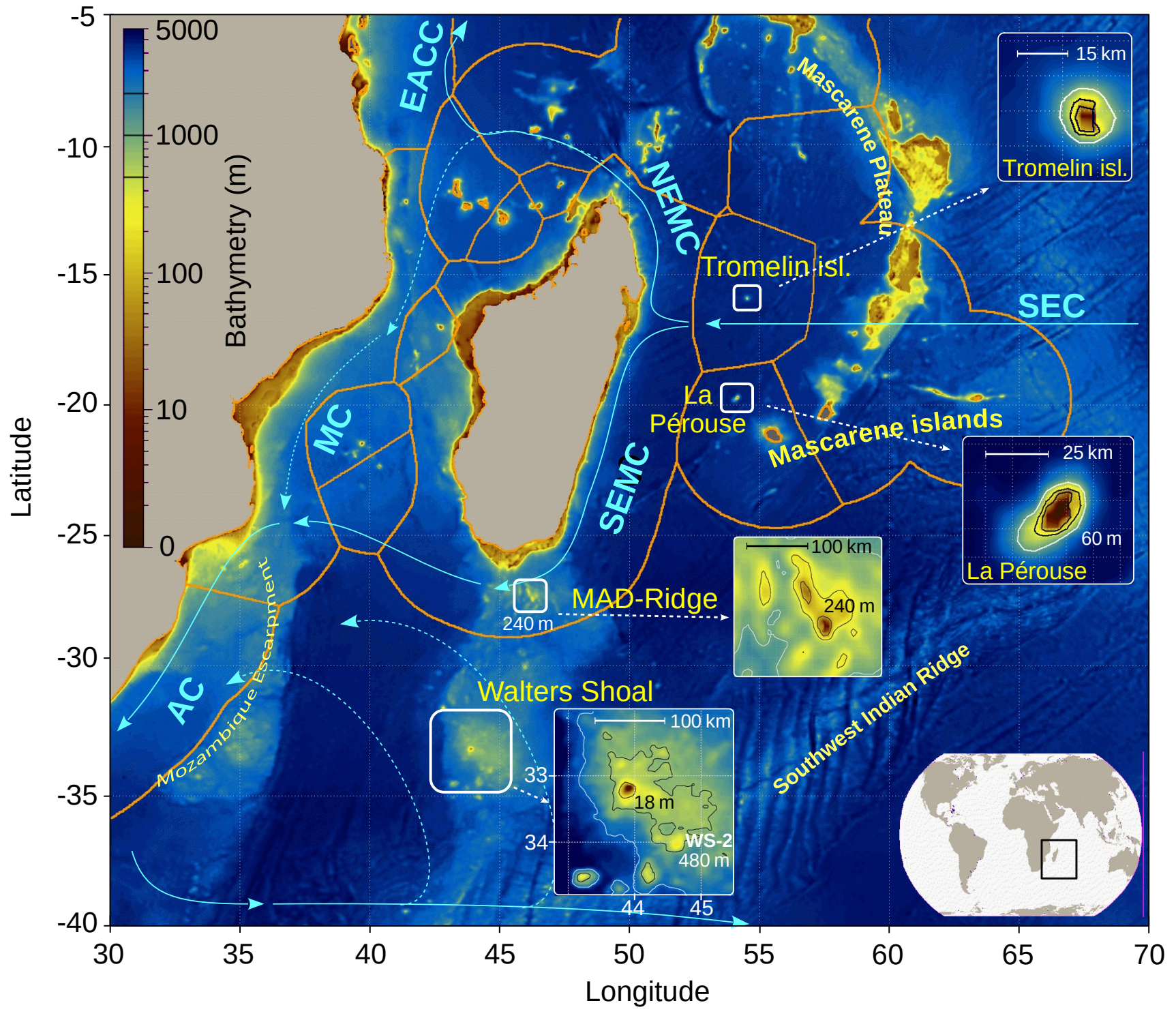

Figure 1 


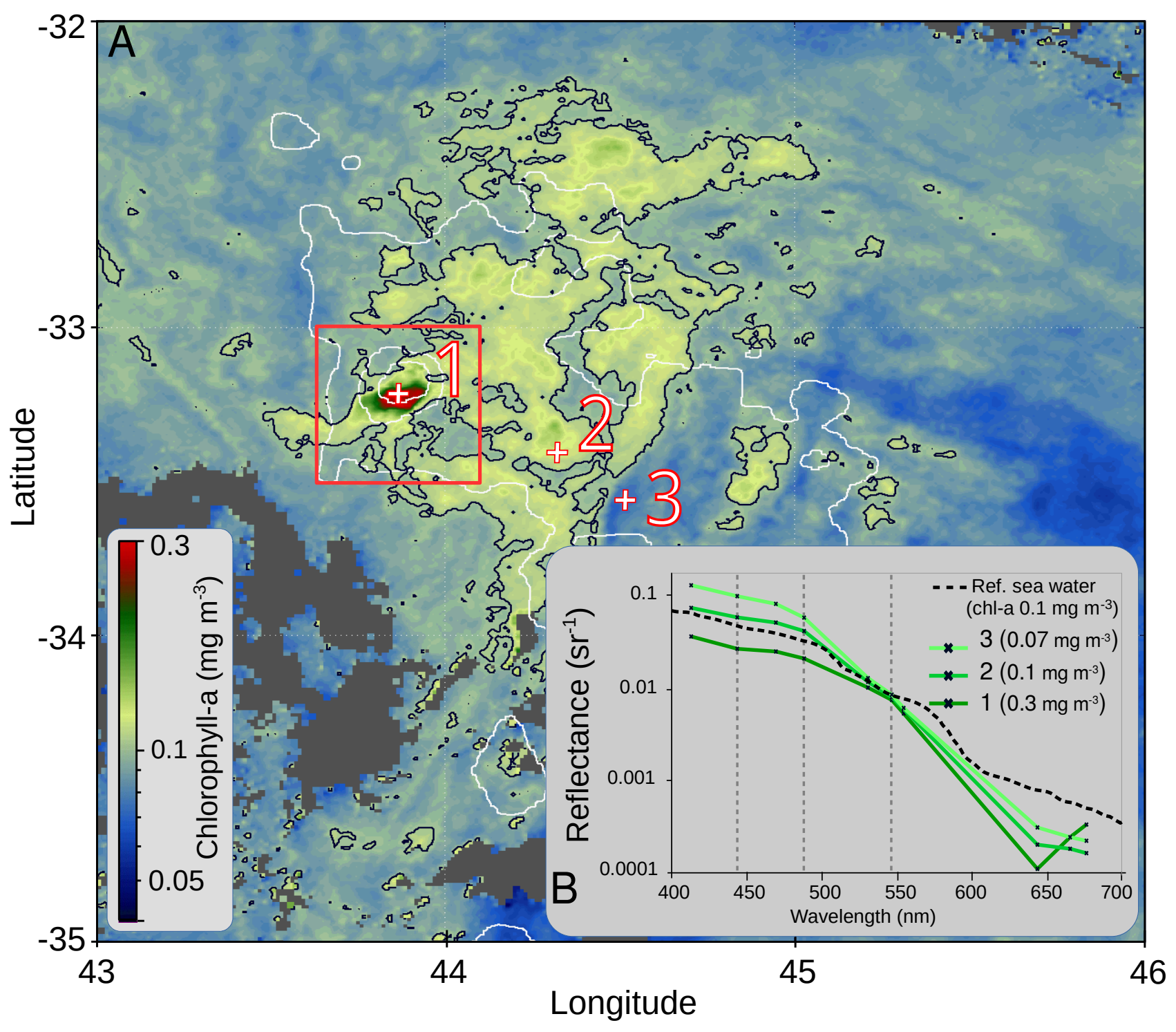

Figure 2 


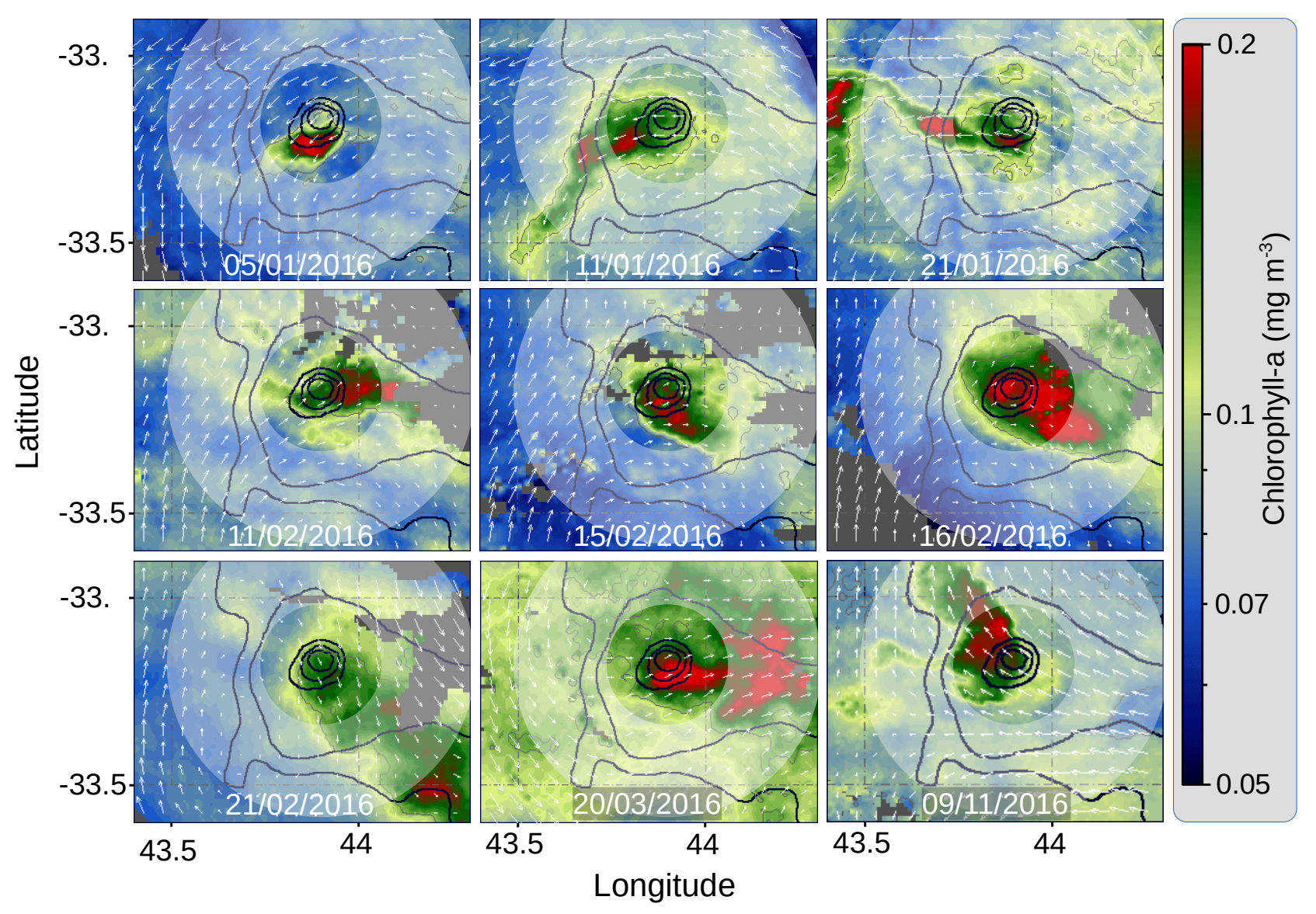

Figure 3 


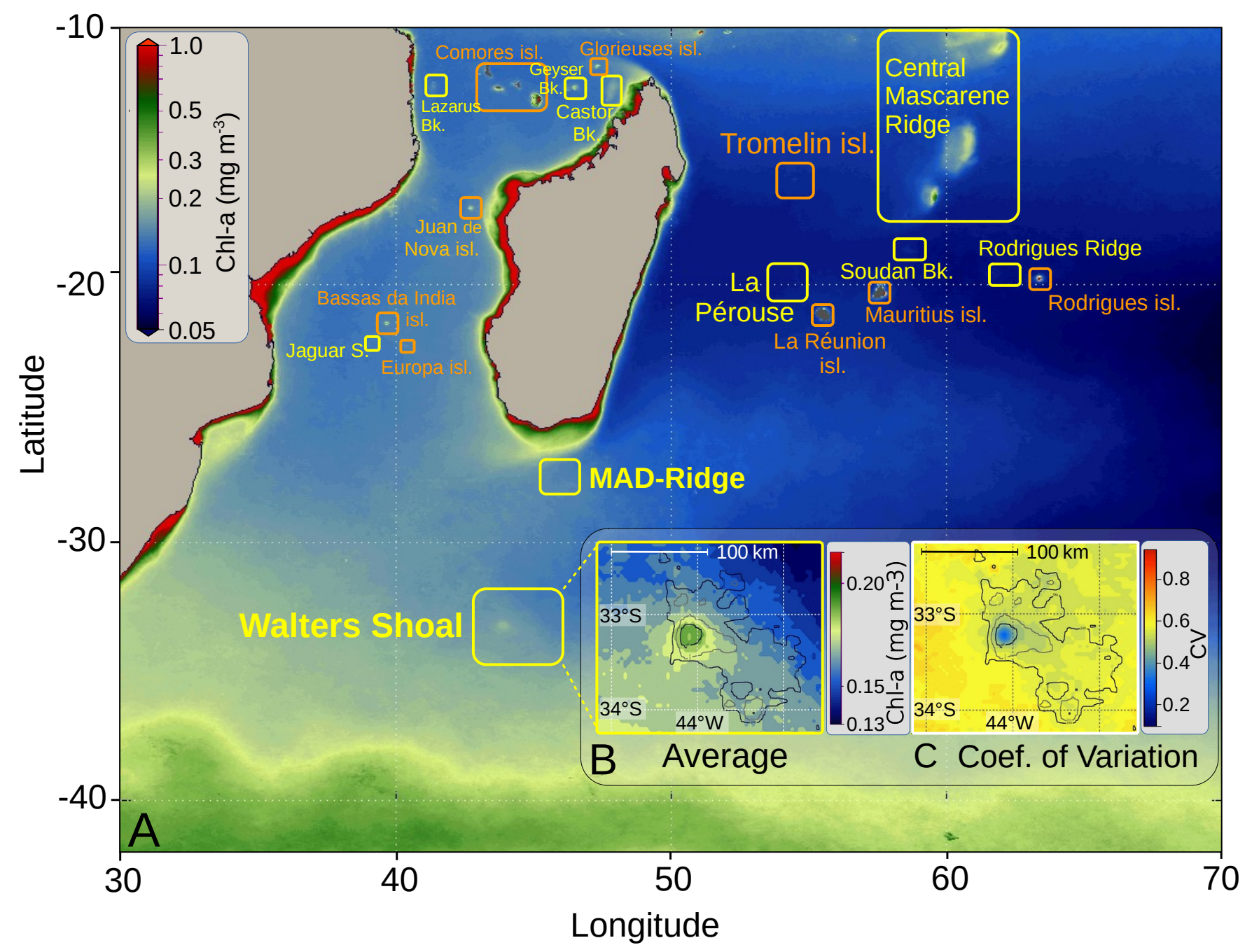

Figure 4 

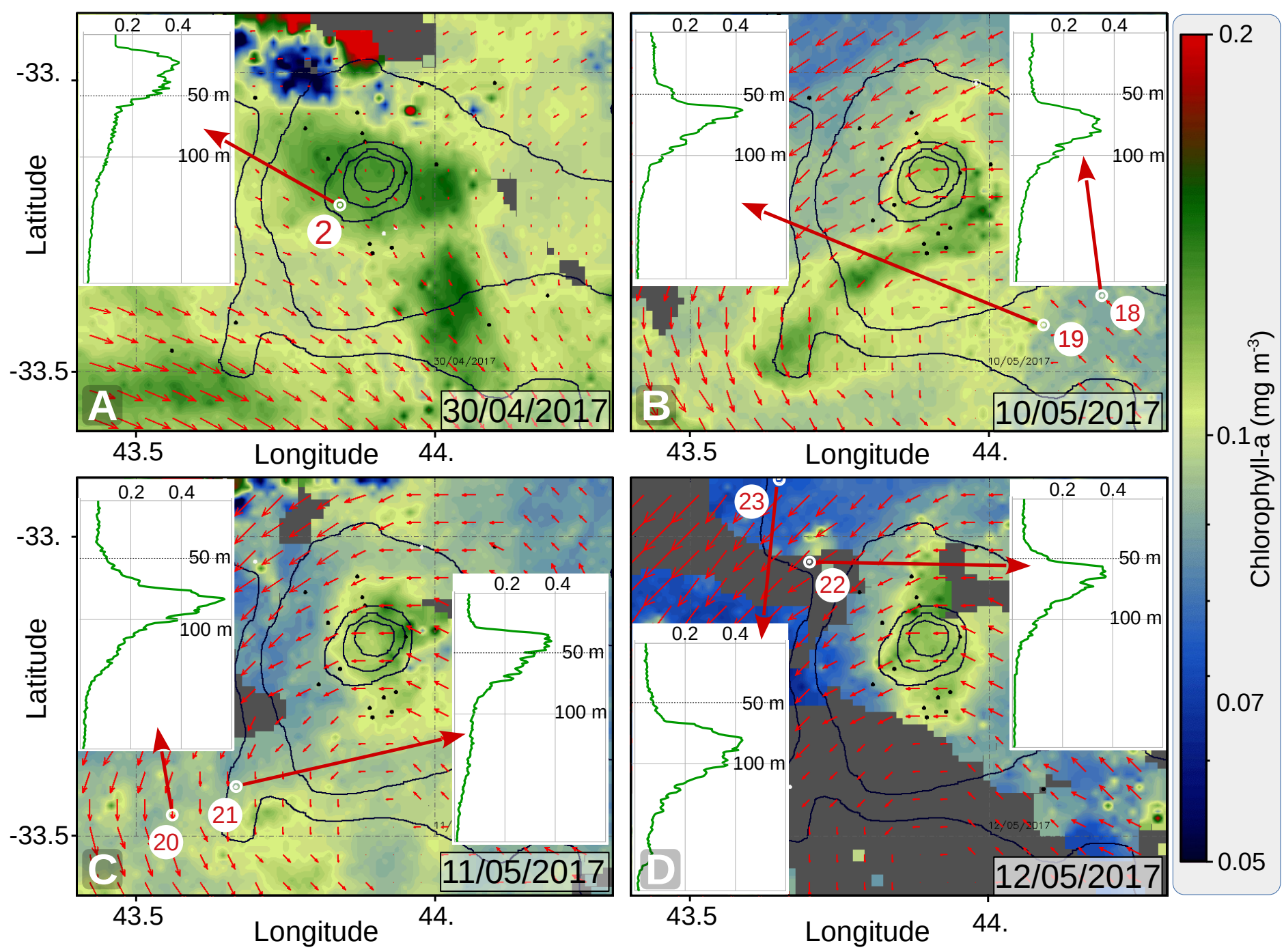

Figure 5 

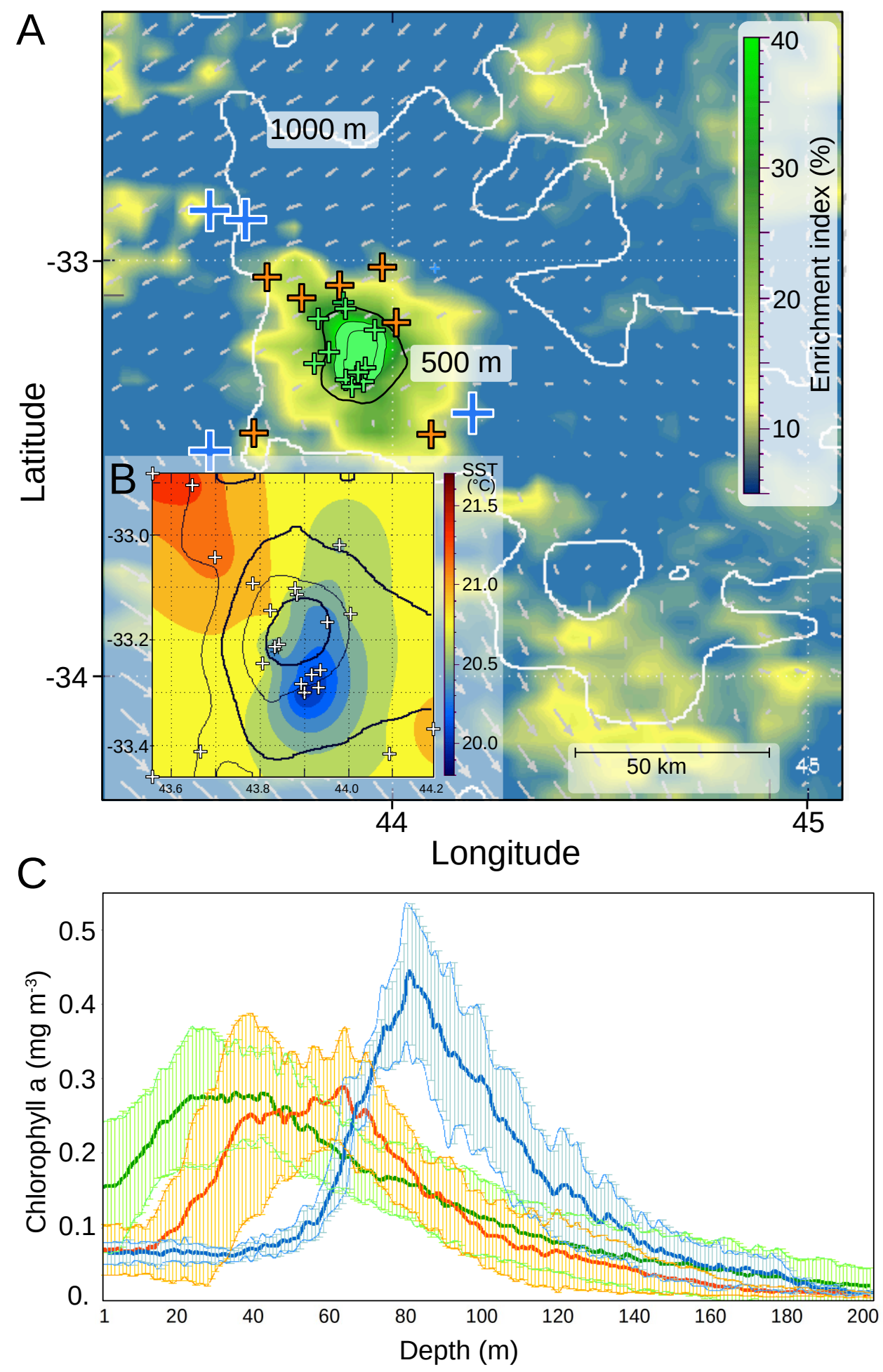

Figure 6 


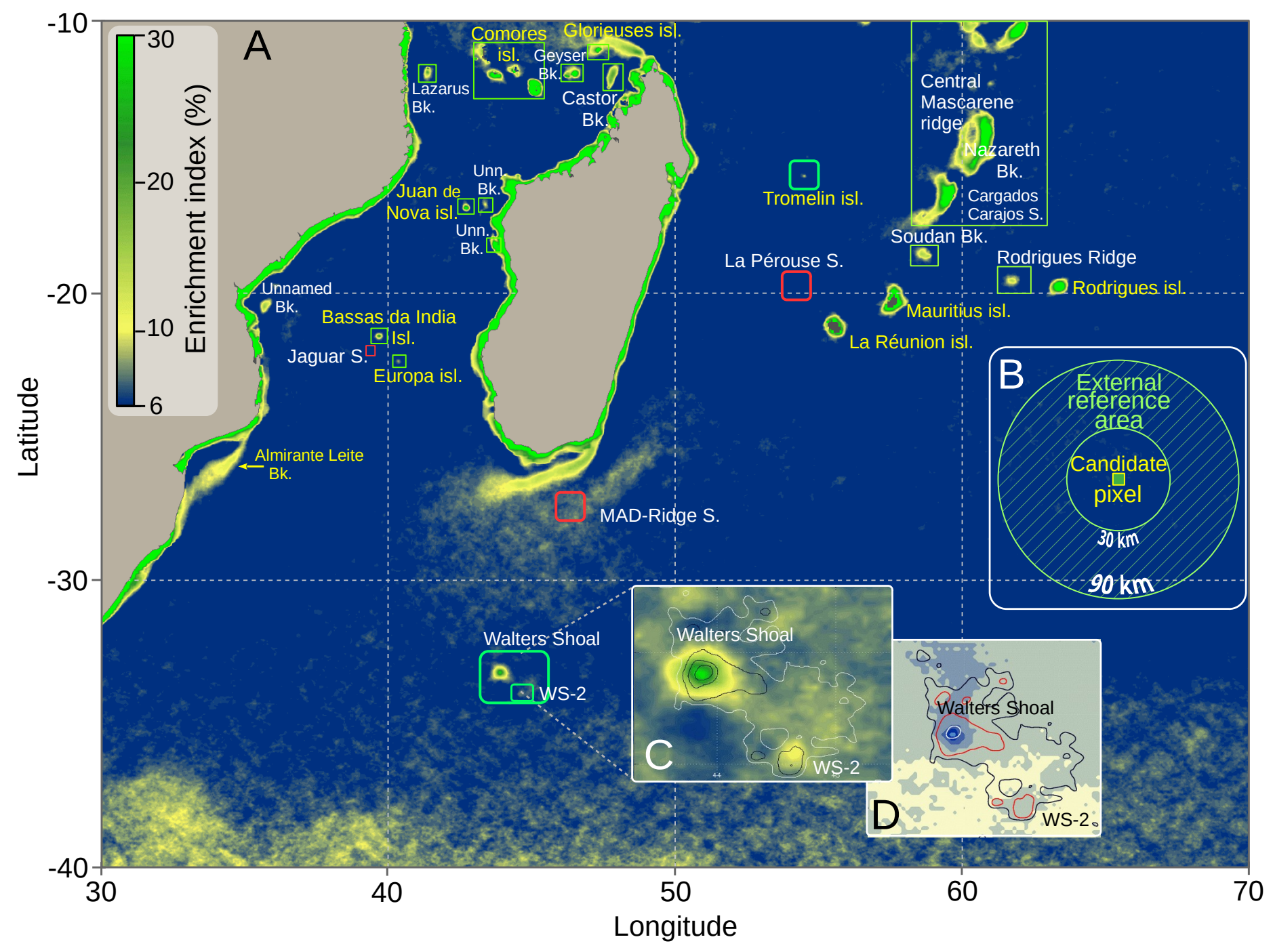

Figure 7 


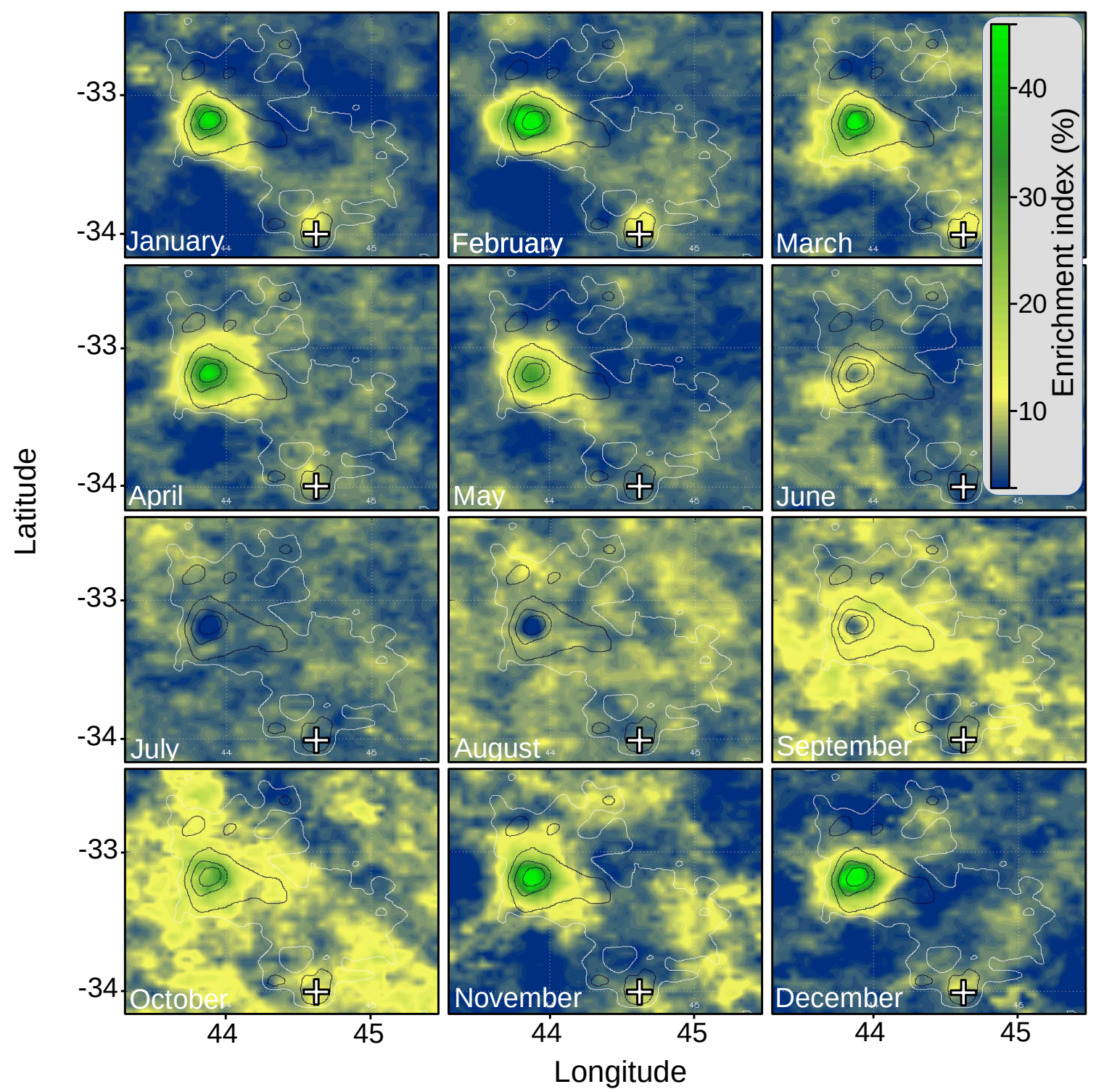

Figure 8 


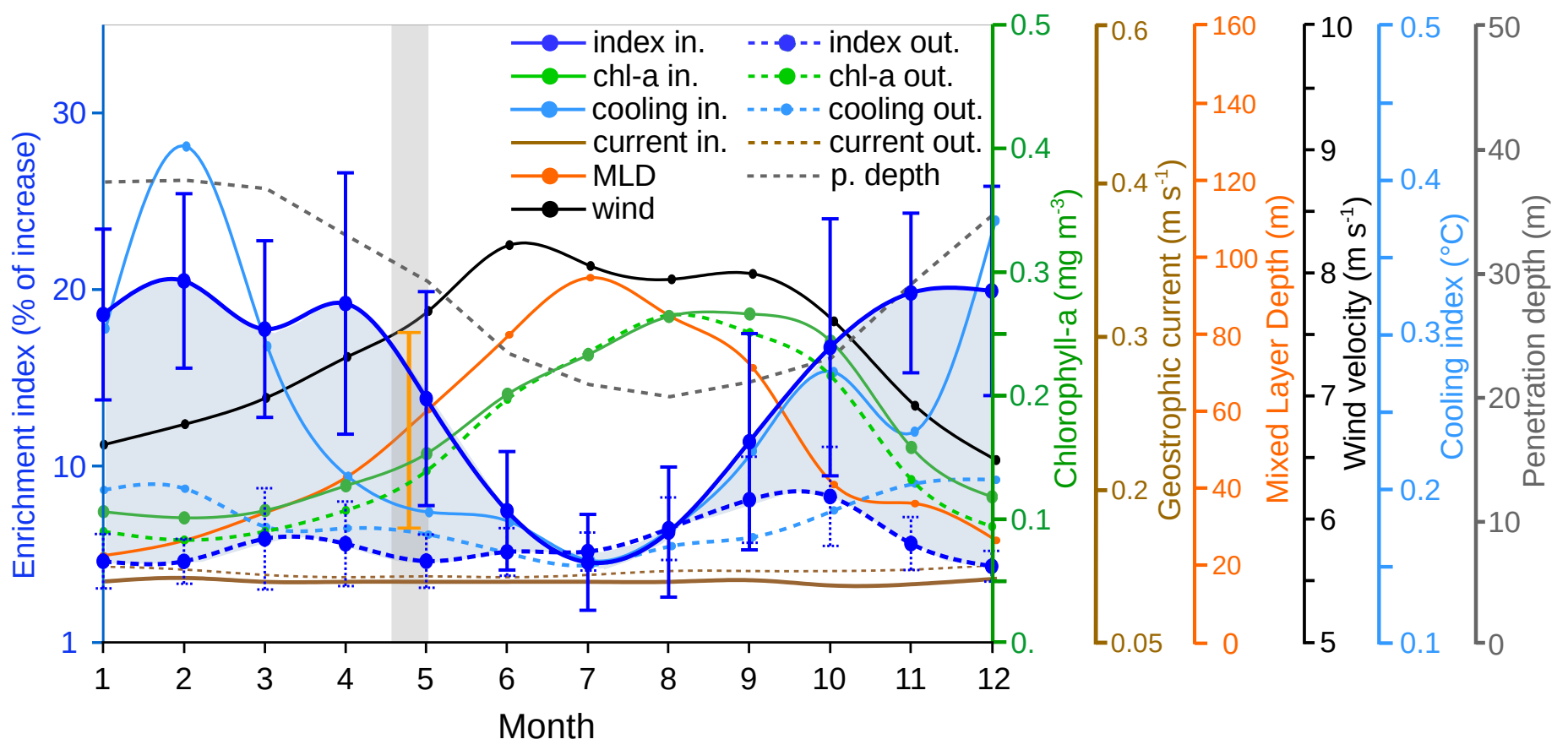

Figure 9 

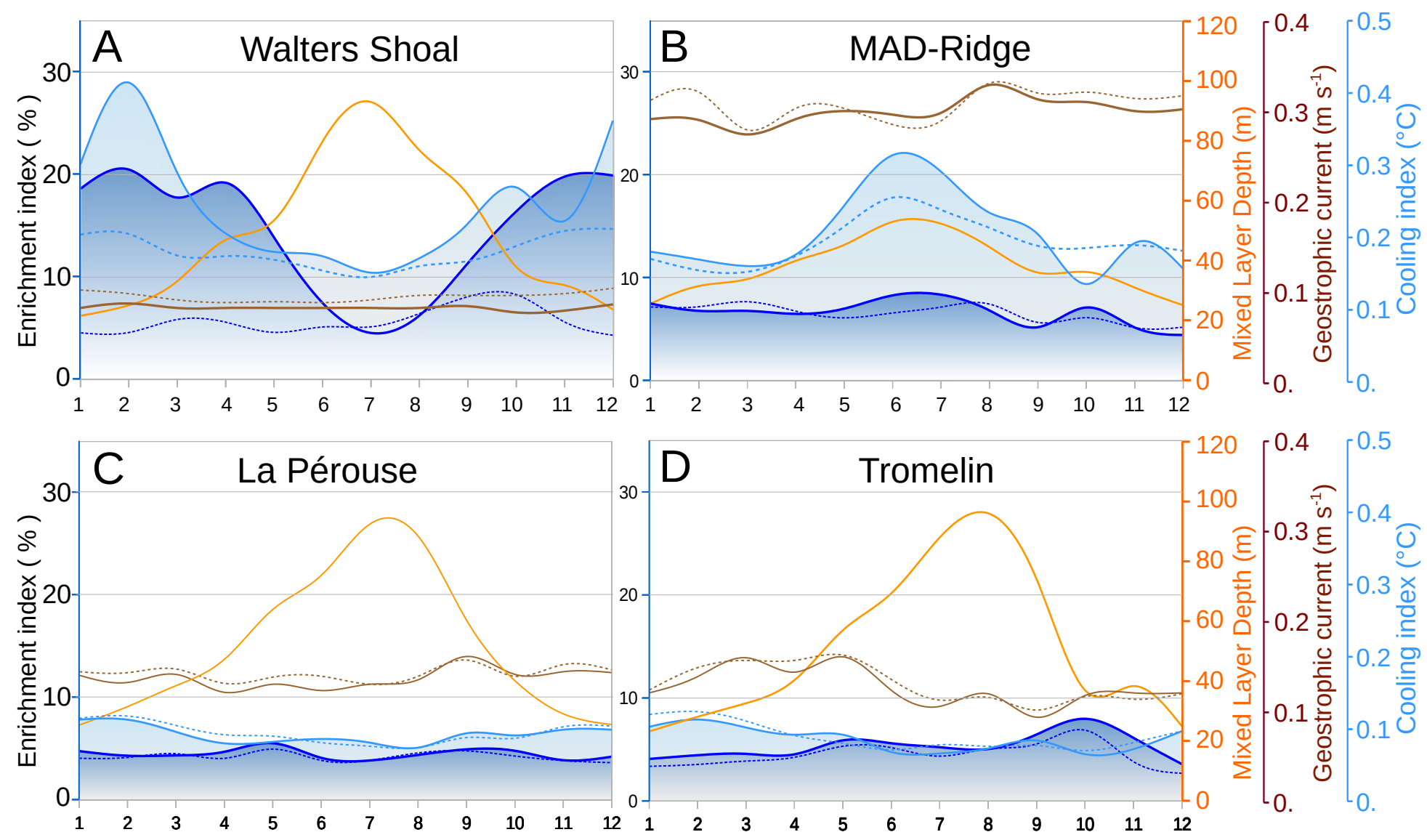

Figure 10 
Table S1.

\begin{tabular}{|c|c|c|c|c|}
\hline \multicolumn{5}{|c|}{ Walters Shoal $(H=650 \pm 50 \mathrm{~m} ;$ depth $=35 \pm 15 \mathrm{~m})$} \\
\hline $\mathrm{U}\left(\mathrm{m} \mathrm{s}^{-1}\right)$ & 0.1 & 0.25 & 0.4 & 0.5 \\
\hline $\mathrm{L}(\mathrm{m})$ & \multicolumn{4}{|c|}{$[25000 \mathrm{~m}-33000 \mathrm{~m}]$} \\
\hline $\mathrm{Ro}=\mathrm{U} /\left(f^{\star} \mathrm{L}\right)$ & $0.04 \pm 0.006$ & $0.11 \pm 0.023$ & $0.17 \pm 0.029$ & $0.22 \pm 0.035$ \\
\hline $\mathrm{BI}=(\mathrm{hO} / \mathrm{H}) / \mathrm{Ro}$ & $21.8 \pm 3.7$ & $8.7 \pm 1.5$ & $5.5 \pm .9$ & $4.4 \pm 0.7$ \\
\hline \multicolumn{5}{|c|}{ MAD-Ridge $(H=[1600,2000,4000] \mathrm{m} ;$ depth $=240 \mathrm{~m})$} \\
\hline $\mathrm{U}\left(\mathrm{m} \mathrm{s}^{-1}\right)$ & 0.5 & 1 & 1.5 & \\
\hline $\mathrm{L}(\mathrm{m})$ & \multicolumn{3}{|c|}{$[50000 \mathrm{~m}-27500 \mathrm{~m}]$} & \\
\hline $\mathrm{Ro}=\mathrm{U} /\left(f^{\star} \mathrm{L}\right)$ & 0.27 & 0.54 & 0.81 & \\
\hline $\mathrm{BI}=(\mathrm{hO} / \mathrm{H}) / \mathrm{Ro}$ & $3.29 \pm 0.170$ & $1.65 \pm 0.085$ & $1.10 \pm 0.057$ & \\
\hline \multicolumn{5}{|c|}{ La Pérouse $(H=[3000,5000] \mathrm{m}$; depth $=60 \mathrm{~m})$} \\
\hline $\mathrm{U}\left(\mathrm{m} \mathrm{s}^{-1}\right)$ & 0.3 & 0.5 & 1.0 & 1.5 \\
\hline $\mathrm{L}(\mathrm{m})$ & & $1000 \mathrm{~m}$ & & \\
\hline $\mathrm{Ro}=\mathrm{U} /\left(f^{\star} \mathrm{L}\right)$ & 0.61 & 1.02 & 2.03 & 3.05 \\
\hline $\mathrm{BI}=(\mathrm{hO} / \mathrm{H}) / \mathrm{Ro}$ & $1.61 \pm 0.009$ & $0.97 \pm .006$ & $0.48 \pm 0.003$ & $0.32 \pm 0.002$ \\
\hline \multicolumn{5}{|c|}{ WS-2 $(H=800 \mathrm{~m} ;$ depth $=480 \mathrm{~m})$} \\
\hline $\mathrm{U}\left(\mathrm{m} \mathrm{s}^{-1}\right)$ & 0.1 & 0.25 & 0.4 & 0.5 \\
\hline $\mathrm{L}(\mathrm{m})$ & & $20000 \mathrm{~m}$ & & \\
\hline $\mathrm{Ro}=\mathrm{U} /\left(f^{\star} \mathrm{L}\right)$ & 0.06 & 0.15 & 0.25 & 0.31 \\
\hline $\mathrm{BI}=(\mathrm{hO} / \mathrm{H}) / \mathrm{Ro}$ & 6.5 & 2.6 & 1.6 & 1.3 \\
\hline
\end{tabular}




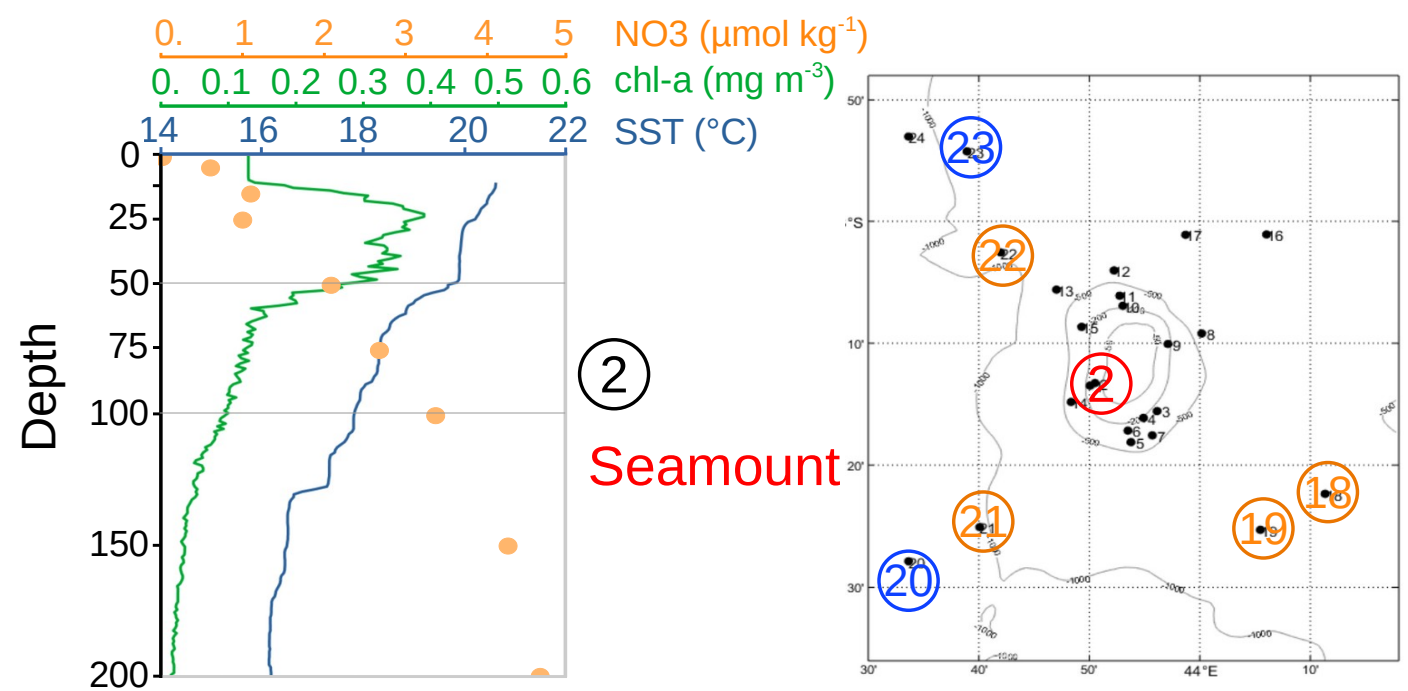

\section{Figure S1}

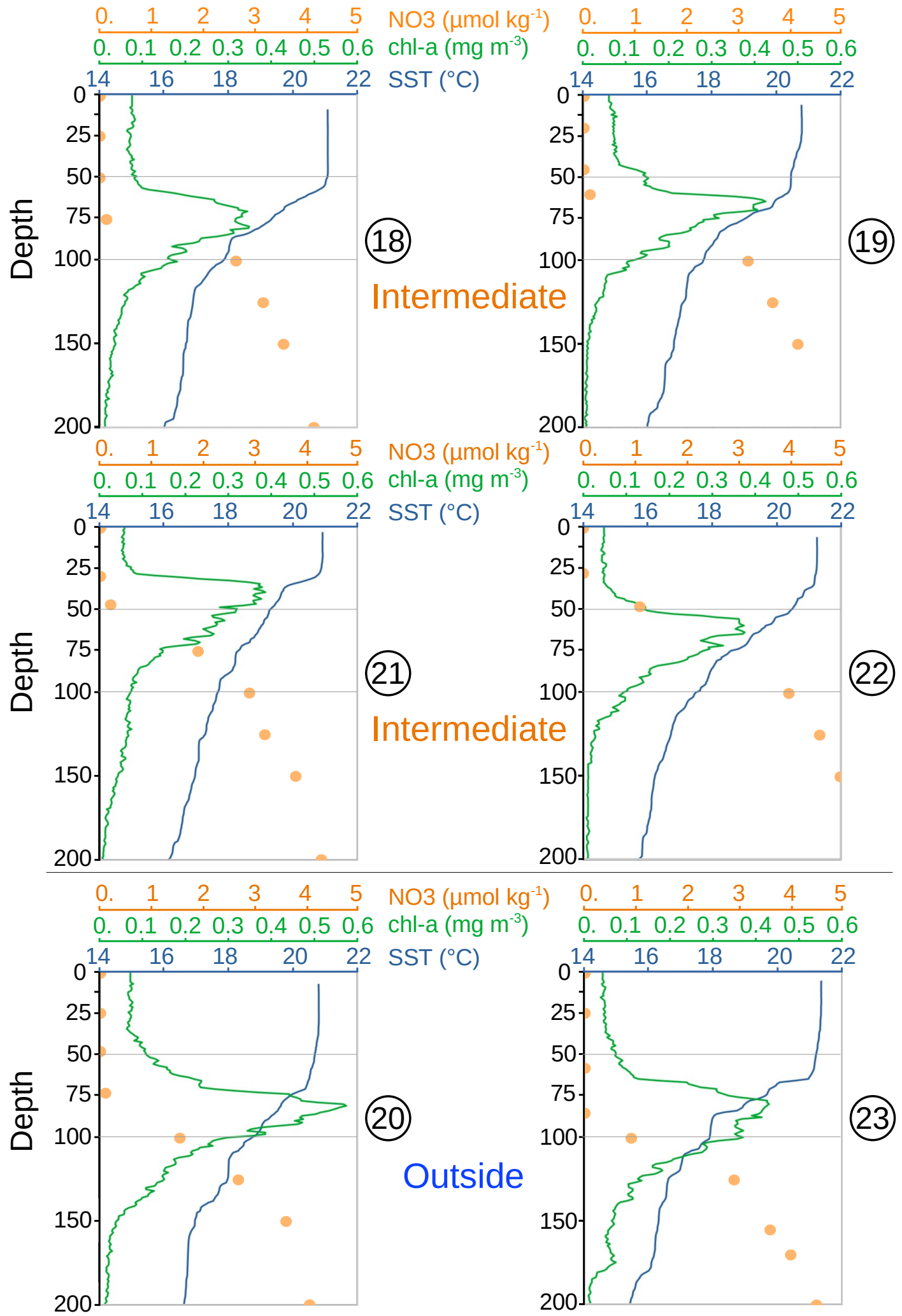




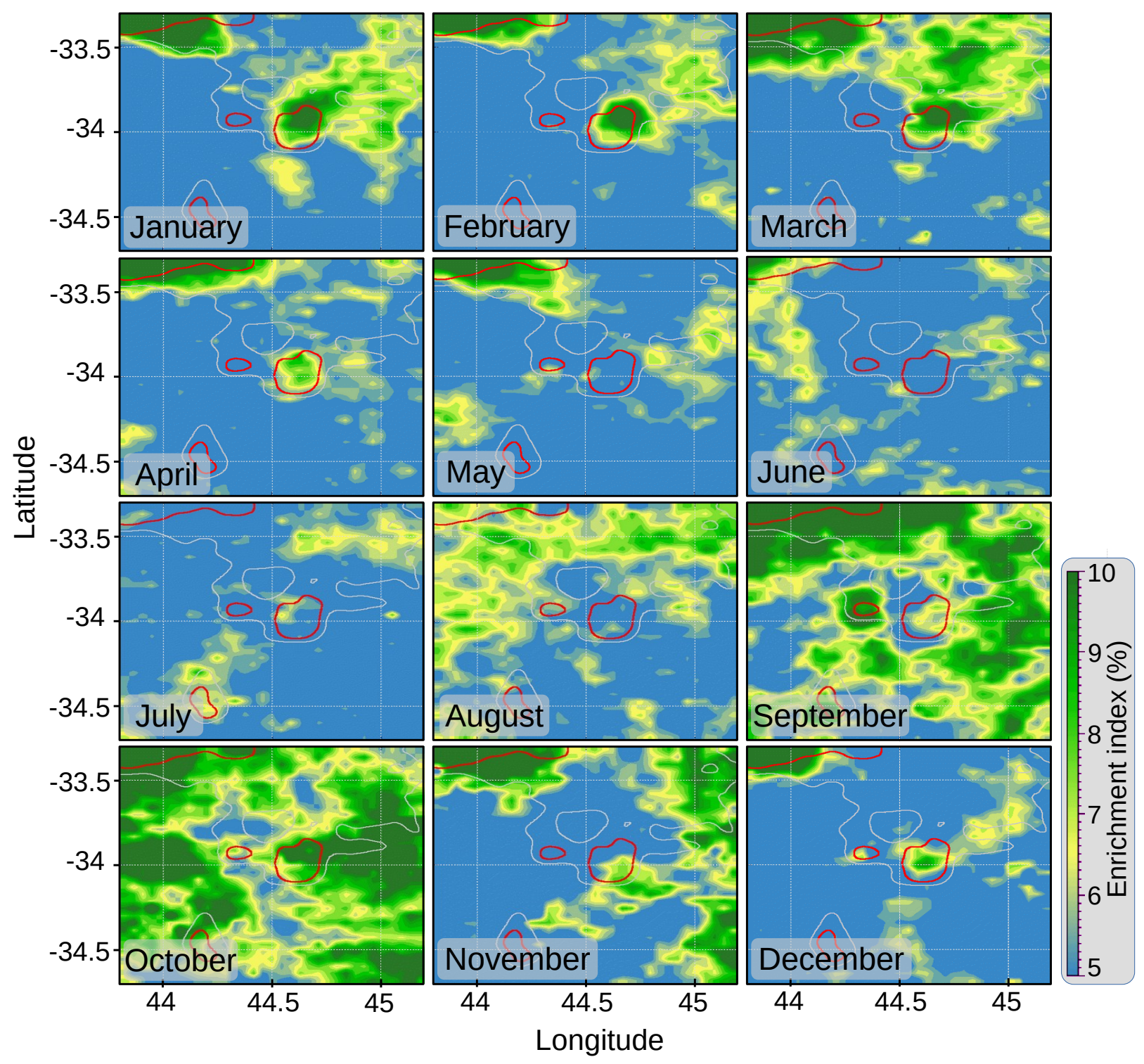

Figure S2 


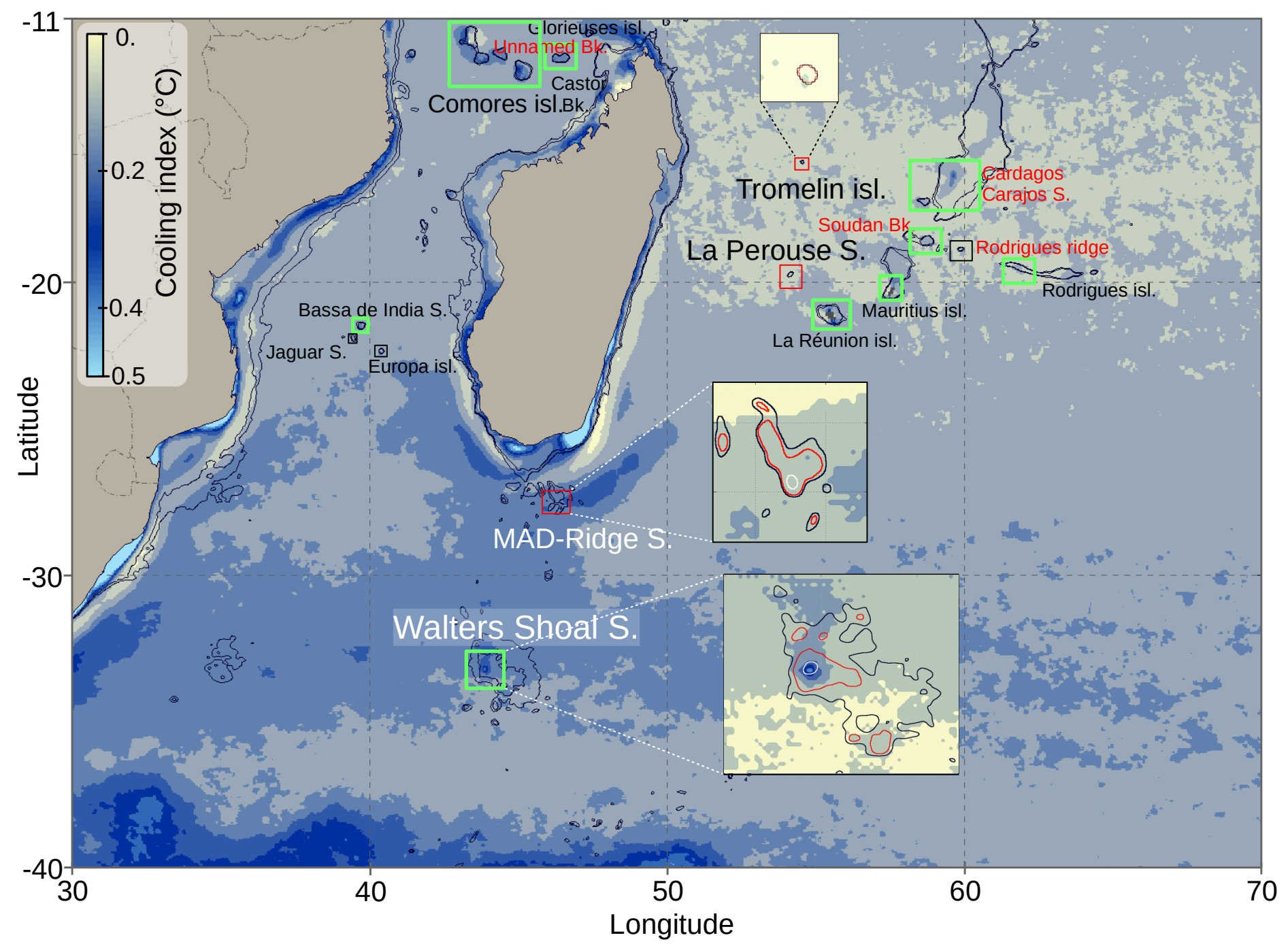

Figure S3 


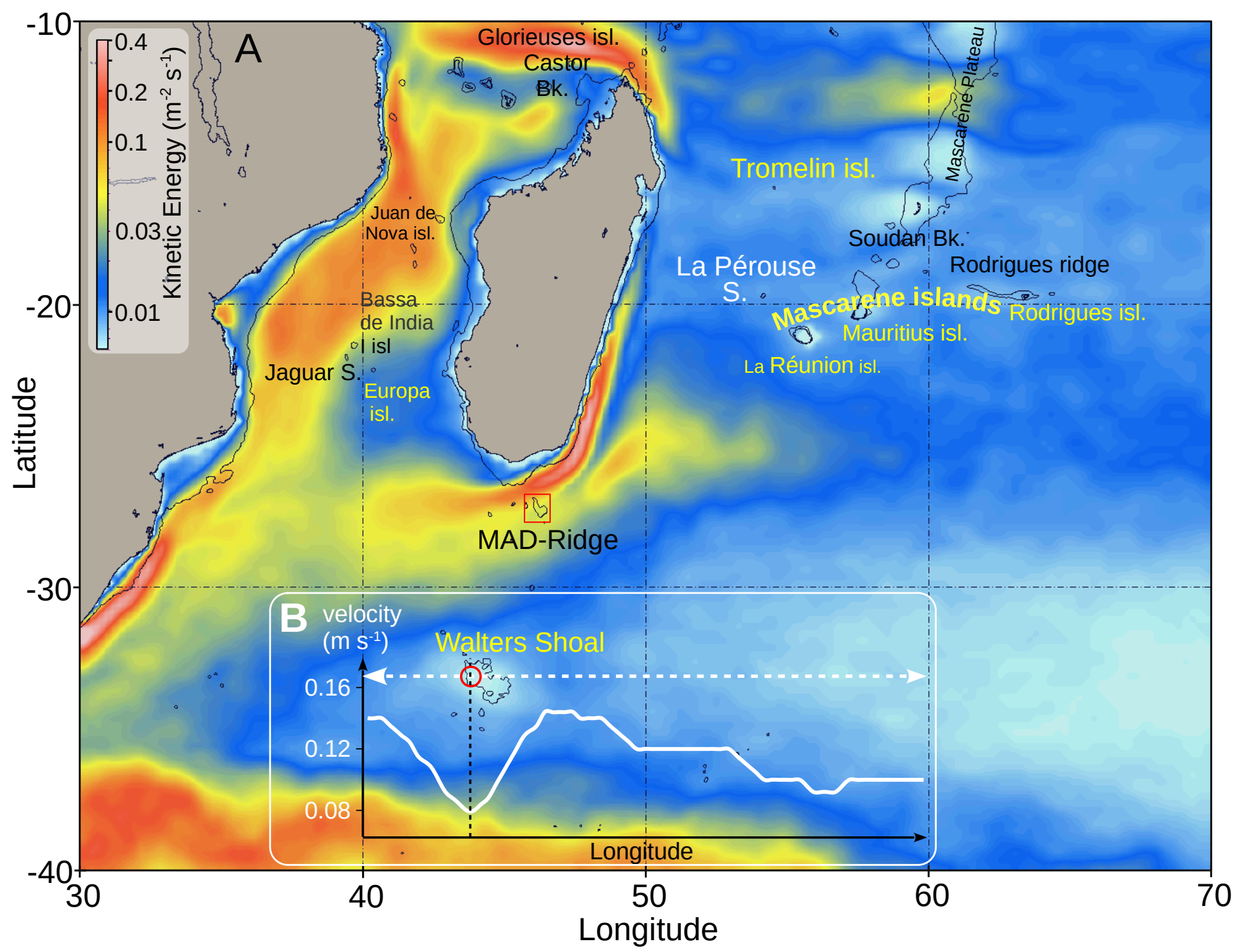

Figure S4 


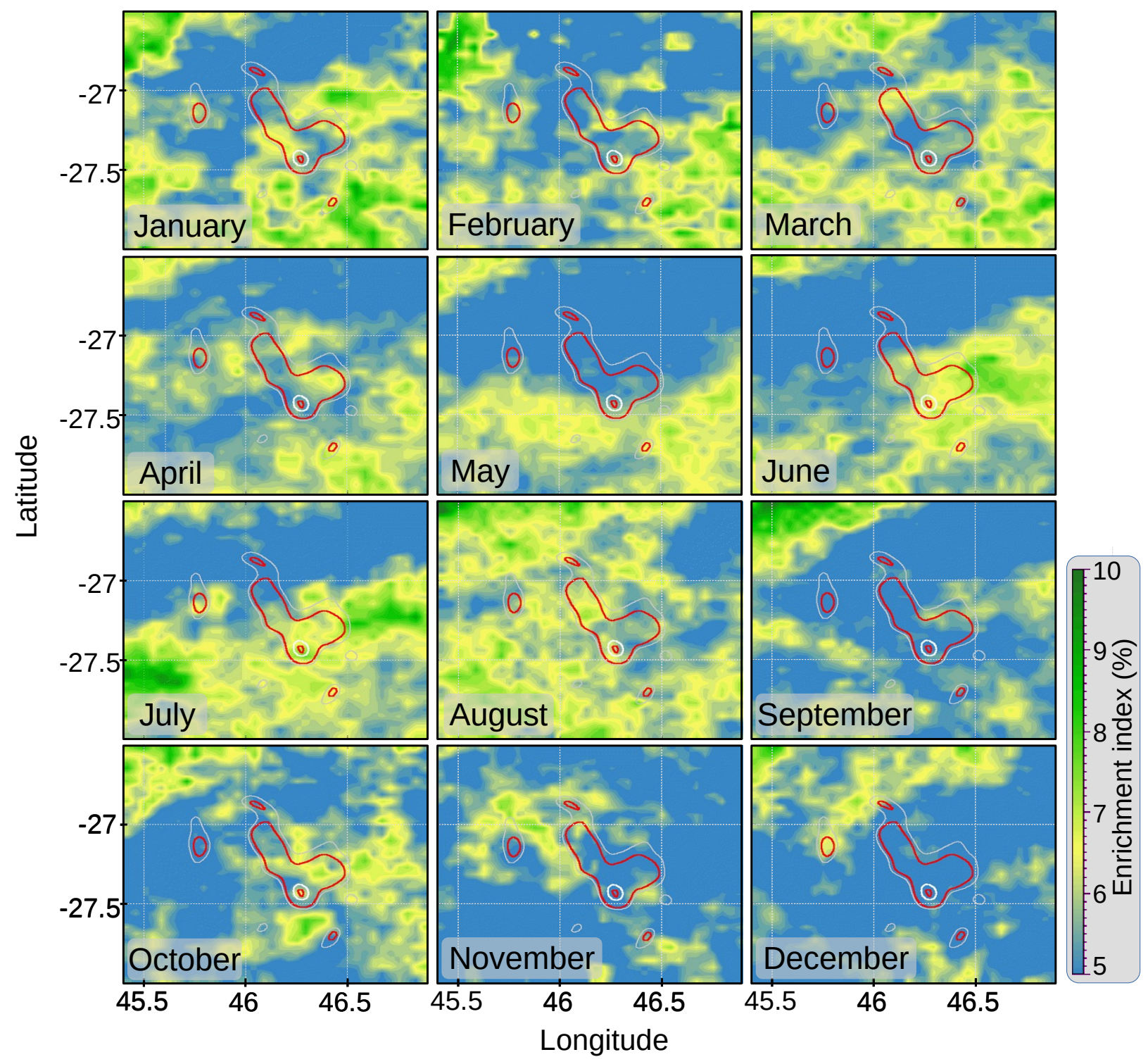

Figure S5 


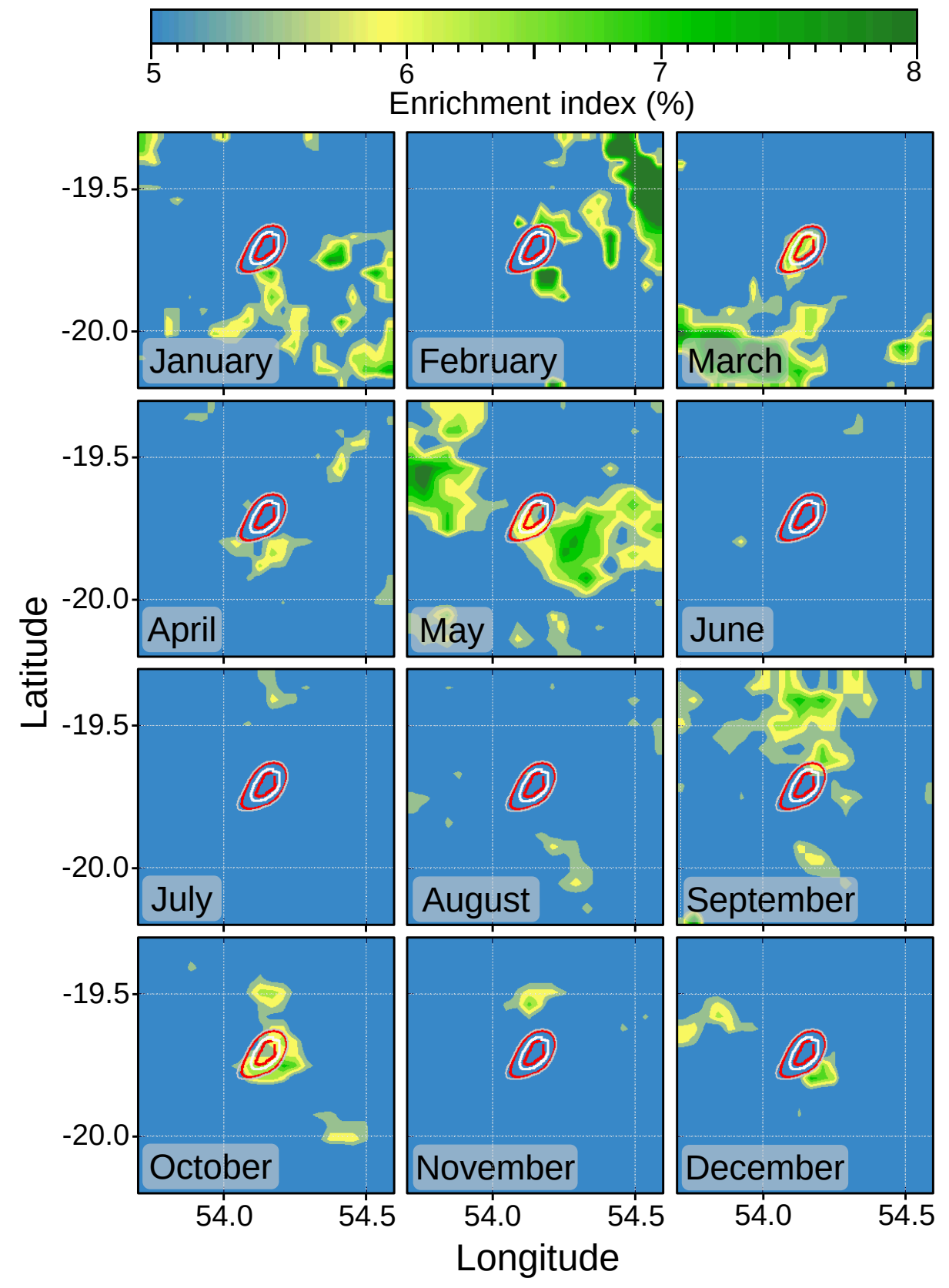

Figure S6 


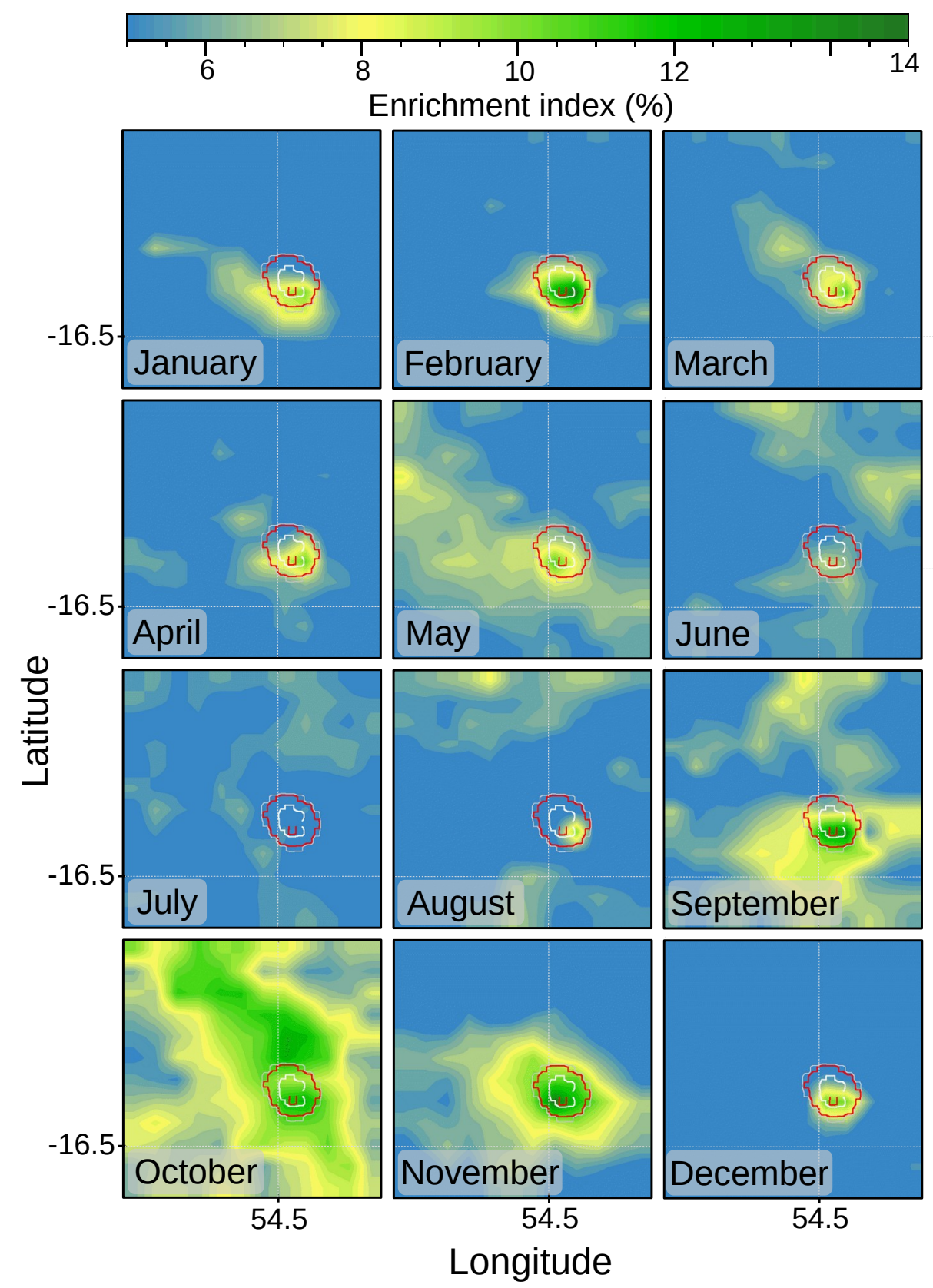

Figure S7 